\title{
Large Eddy Simulations of Complex Multicomponent Diesel Fuels in High Temperature and Pressure Turbulent Flows
}

\begin{abstract}
A multicomponent droplet evaporation model, which discretizes the one-dimensional species and temperature profiles inside a droplet with a finite volume method and treats the liquid phase as thermodynamically real, has been developed and used for large-eddy simulations of high speed diesel sprays in high temperature and pressure closed chambers. Single drop evaporation results obtained by the variable property multicomponent model are shown to match with the constant property model in the limiting conditions. The multicomponent liquid model used together with the Kelvin-Helmholtz - Rayleigh-Taylor droplet breakup model is found to reasonably well predict the experimentally observed non-linear behavior of spray penetration with changing ambient conditions for n-hexadecane and 4 different multicomponent surrogate diesel fuels with 2-8 components. The effects of various modeling assumptions and gas and liquid parameters on the drop and spray evolution and evaporation are investigated in details.
\end{abstract}

Keywords: Multicomponent Evaporation, Complex Fuel Mixtures, LES

\section{Introduction}

Vaporization of liquid fuels and its prediction is of fundamental importance in many engineering applications, particularly in internal combustion engines and other propulsion systems. The type of model used for predicting the evaporation of liquid droplets can have a significant effect on the spatial and temporal distribution of the fuel in the vapor phase and consequently the combustion. In most spray calculations conducted with direct numerical simulation (DNS) or large eddy simulation (LES) methods [1]-[8], the modeling approach to heat transfer and evaporation has been that of assuming the fuel to be composed of a single component with lumped properties. This assumption has been convenient numerically and has been widely utilized. However, for multicomponent fuels like gasoline, diesel or biodiesels, more complex multicomponent evaporation models are usually needed. The presence of components with a wide range of volatility and the consequent non-monotonicity of the mass fraction and temperature profiles inside the fuel droplet makes it imperative to resolve the physico-chemical features of all multicomponent components.

Various single component and multicomponent models have been proposed over the years for the droplet evaporation [9], [10]. These models can be divided into two different types: discrete-component and continuous thermodynamics models. Continuous thermo- dynamic models, originally developed by Tamim and Hallett [11], use a continuous distribution function to model the complex fuel composition. This distribution function is based on properties like molecular weight or boiling point and is used for the evaluation of the multicomponent fuel properties. The continuous models have much less computational overhead but are relatively difficult to be used for combustion simulations. Nevertheless, they have been used in several studies in the past in both original and modified forms [12]-[15]. For example, Zhang et al.[15] have developed a hybrid model using continuous thermodynamics to describe the petroleum fuel and the discrete components approach to represent the biofuels in a petroleum-biofuel blend. Discrete component models characterize the complex fuel as a mixture of several representative species and track the individual components during the evaporation process. This allows coupling of the evaporation process with the combustion and comprehensive reaction mechanisms. References [16] - [24] present some of the discrete component models used for multicomponent evaporation. Landis and Mills [16] studied the spherically symmetric evaporation of a heptane-octane droplet in air and concluded that the evaporation becomes quasisteady after the early transition, with both components evaporating at a rate nearly proportional to their initial mass fractions. Lara-Urbaneja and Sirignano [18] developed a model for studying the transient evaporation 
of liquid droplets. The gas and liquid phase boundary layers in this model were analyzed by an integral method and the mass and heat transfer in the droplet core were described by a vortex model. They found that the internal circulation and higher mixture volatility reduce the nonuniformity inside the droplet. Aggarwal [19] analyzed the effects of different liquid and gas phase models for a dilute spray in a laminar, hot gas stream and found the results to be sensitive to the model used. The model with infinitely fast diffusion overpredicted and underpredicted the vapor mass fractions of the most volatile and the least volatile components, respectively. The model with limited diffusion gave better predictions due to its ability to resolve the internal liquid temperature and mass fraction profiles. Chen et al. [20] studied the evaporation of multicomponent fuels in laminar flows and concluded that for relatively low ambient temperatures, both the models with finite and infinite diffusion yield good results, provided that variable properties are used in both the liquid phase and the gas film surrounding the droplet. Renksizbulut and Bussmann [21] studied the droplet evaporation with an axisymmetric model and concluded that the liquid phase mass transfer is highly transient with preferential vaporization of more volatile species and that a constant Lewis number approximation is not valid. They also found that the commonly used correlations for the drag coefficient and Nusselt and Sherwood numbers are reasonably accurate for multicomponent droplet evaporation predictions at intermediate Reynolds numbers ( 100). Zeng and Lee $[22,23]$ developed a multicomponent droplet model which solves the difference equations between surface and average temperatures and mass fractions and uses polynomial functions for the inner droplet temperature and mass fractions. In the work by $\mathrm{Ra}$ and Reitz [24], an approximate solution of the quasi-steady energy equation is used to calculate the heat flux from the gas to the droplet. The model considers finite heat transfer rates but assumes the liquid phase to be well mixed in both normal or flash-boiling conditions. Experimental techniques for measuring fuel vapor distribution for diesel sprays include laser-induced fluorescence (LIF) in which a non-fluorescent fuel is mixed with a fluorescent tracer. Vapor distribution measurements for diesel sprays are generally difficult due to issues of de-mixing of the fuel tracer from the fuel due to difference in properties at high temperature and pressure conditions [25]. Data for SI engine conditions is more readily available [25] -[29]. Zigan et al. [25] employed a combination of 2D-Mie scattering, LIF and phaseDoppler anemometry (PDA) to study the spray formation and evaporation dependence on fuel properties for a Direct Injection Spark Ignition (DISI) engine. Various single component alkanes with different volatilities and a 3 component gasoline surrogate were tested under late injection conditions and it was found that high volatility fuels destabilize the spray due to high evaporation rates while low volatility fuels have higher radial spread. The multicomponent fuel behavior was between the two limiting conditions of distillation-like behavior and co-evaporation. The study emphasized the importance of multicomponent evaporation models which include mixing within the droplets to properly predict the spray behavior at high pressure conditions. Twocolor toluene LIF was utilized by Tea et al. [30] to obtain temperature measurements of the unburned fuel/air mixture in diesel sprays which can be used to infer the vapor phase distribution. However, this technique has some limitations at temperatures above $700 \mathrm{~K}$. Trost et al. [31] recently used 1-methylnaphthalene planar laserinduced fluorescence (PLIF) to study fuel concentration for pilot injections of diesel primary reference fuels cetane and iso-cetane in an optically accessible diesel engine. Equivalence ratio of the evaporated fuel was measured at different planes and crank angles, however stratification of the fuels was not studied.

A stochastic breakup model [32] has recently been implemented by Irannejad et al. [33, 34], along with the multicomponent evaporation model and a droplet wake model for detailed study of high speed sprays in high temperature and pressure systems via LES. The droplet wake model considers the wake effect of leading droplets on the felt relative velocity of the trailing droplets and is based on concepts developed in Silverman and Sirignano [35]. The LES study presented an improved prediction of the liquid and evaporated spray length, and discussed in detail the relative importance of grid resolution, droplet wake model, and subgrid turbulence and particle models on the spray/drop dynamics. The overall conclusion was that all these parameters are important and should be considered along with a reliable breakup model for better prediction of realistic fuel sprays.

The high rate of fossil fuel consumption has been a major contributor to greenhouse emissions and environmental pollution. This and limited availability of fossil fuels have led to considerable research into the development of alternative fuels like plant-derived biofuels with lower environmental impacts. Some of the alternatives being studied are liquid and gaseous fuels derived from biomass including biodiesel, bioethanol, biomethanol, etc. ([36], [37], [38]). Soy- and Canoladerived biodiesels have been the subject of many studies aimed at the evaluation of the fuel's performance in en- 
gines and modeling of the fuel's combustion ([39]-[44]).

The main objective of this paper is to develop physically sound but practical multicomponent droplet heat and mass transfer models for numerical simulations of highly evaporative liquid fuels in harsh environment. For this we use a Lagrangian spray model with onedimensional, finite rate, variable-property solvers for the heat transfer and evaporation inside all simulated droplets. The droplet model is used together with compressible LES model for predictions of measured liquid quantities of high speed evaporating turbulent sprays at various high temperature and pressure gas conditions. Comparison of global vapor phase quantities like vapor penetration for single component fuels has been carried out with the current evaporation model in an aforementioned study [34] and is not considered here. Comparison of vapor phase distribution with experimental data for multicomponent diesel fuels has not been carried out and would be the subject of future studies.

\section{Mathematical Formulation and Computational Models}

The multicomponent evaporation model we use in our LES calculations is based on that developed by Torres et al. [45, 46, 47] and used for simpler simulations. The model discretizes the radial and symmetric profiles of the time-dependent temperature and mass fractions inside each droplet and solves them with a finite volume numerical method. The model has been modified to treat the liquid phase as real by using activity coefficients using the UNIversal Functional Activity Coefficient (UNIFAC) method. In the following, the multicomponent model is described in details after describing the simpler single-component model and before discussing the gas-phase LES equations.

\subsection{Single-Component droplet model}

The following Lagrangian equations [2] describe the transient position $\left(x_{i}\right)$ and velocity $\left(v_{i}\right)$ of a droplet:

$$
\begin{gathered}
\frac{d x_{i}}{d t}=v_{i}, \\
\frac{d v_{i}}{d t}=\frac{F_{i}}{m_{d}}=\frac{f_{1}}{\tau_{d}}\left(u_{i}-v_{i}\right),
\end{gathered}
$$

The Lagrangian equations for the temperature and mass of the droplet in the constant property, singlecomponent lumped model [2] are:

$$
\begin{gathered}
\frac{d T_{d}}{d t}=\frac{Q+\dot{m}_{d} L_{v}}{m_{d} C_{p, l}}=\frac{N u_{g}}{3 \operatorname{Pr}_{g}}\left(\frac{C_{p, g}}{C_{p, l}}\right)\left(\frac{f_{2}}{\tau_{d}}\right)\left(T_{g}-T_{d}\right) \\
+\left(\frac{\dot{m}_{d}}{m_{d}}\right) \frac{L_{v}}{C_{p, l}},
\end{gathered}
$$

$$
\frac{d m_{d}}{d t}=\dot{m}_{d}=-\frac{S h_{g}}{3 S c_{g}}\left(\frac{m_{d}}{\tau_{d}}\right) \ln \left[1+B_{M}\right],
$$

In these equations, $m_{d}$ is the mass of the droplet, $T_{d}$ is the temperature of the droplet, $T_{g}$ is the gas phase temperature at the droplet location, $L_{v}$ is the latent heat of vaporization of the liquid fuel, $C_{p_{l}}$ is the heat capacity of the liquid, and $C_{p_{g}}$ is the heat capacity of the gas phase which is calculated as,

$$
C_{p, g}=\left(1-Y_{v}\right) C_{p, c}+Y_{v} C_{p, v}
$$

Here, $Y_{v}$ is the mass fraction of the evaporated vapor, $C_{p, c}$ is the heat capacity of the carrier gas and $C_{p, v}$ is the heat capacity of the evaporated vapor. The mass transfer number $B_{M}$, the droplet characteristic time $\tau_{d}$, and the gas phase Prandtl, Schimdt, Nusselt and Sherwood numbers, are obtained from the following equations:

$$
\begin{gathered}
B_{M}=\frac{Y_{v, s}-Y_{v}}{1-Y_{v, s}}, \\
\tau_{d}=\frac{\rho_{l} d^{2}}{18 \mu_{g}} \\
P r_{g}=\mu_{g} C_{p, g} / \lambda_{g}, S c_{g}=\mu_{g} /\left(\rho_{g} D_{v}\right) \\
N u_{g}=2+0.552 \operatorname{Re}_{s l}^{1 / 2} \operatorname{Pr}_{g}^{1 / 3} \\
S h_{g}=2+0.552 \operatorname{Re}_{s l}^{1 / 2} S c_{g}^{1 / 2}
\end{gathered}
$$

where $Y_{v, s}$ is the vapor mass fraction at the droplet surface, $\rho_{l}$ is the liquid fuel density, $\mu_{g}$ is the gas viscosity and $R e_{s l}$ is the Reynolds number based on the droplet slip velocity.

\subsection{Multicomponent droplet model}

The multicomponent model used in this work tracks the evolution of temperature and all species mass fractions inside a spherically symmetric droplet. The heat and mass diffusions are assumed to be based on Fourier and Fickian assumptions. Internal circulation caused by the relative motion between the gas and the liquid is accounted for by using effective mass and thermal liquid diffusivities. The fuel densities are temperature dependent and the advective terms related to the expansion velocities due to fuel density changes are included. The enthalpy diffusion terms in the liquid internal energy equations are also retained. The gas phase temperature and mass fraction gradients are modeled using Nusselt and Sherwood numbers. Other assumptions include insolubility of the gas phase in the liquid and the use of Raoult's law for vapor-liquid phase equilibrium, which has been modified here, as explained later. Soret and Dufour effects and thermal radiation are ignored. 
With the above assumptions, the conservation equations for the droplet density, species mass fractions and energy in the liquid phase may be written as,

$$
\begin{gathered}
\frac{\partial \rho_{l}}{\partial t}+\frac{1}{r_{l}^{2}} \frac{\partial}{\partial r_{l}}\left(r_{l}^{2} \rho_{l} v_{l}\right)=0 \\
\frac{\partial\left(\rho_{l} Y_{l, k}\right)}{\partial t}+\frac{1}{r_{l}^{2}} \frac{\partial}{\partial r_{l}}\left(r_{l}^{2} \rho_{l} v_{l} Y_{l, k}\right)=\frac{1}{r_{l}^{2}} \frac{\partial}{\partial r_{l}}\left(r_{l}^{2} \rho_{l} D_{l} \frac{\partial Y_{l, k}}{\partial r_{l}}\right), \\
\frac{\partial\left(\rho_{l} T_{l}\right)}{\partial t}+\frac{1}{r_{l}^{2}} \frac{\partial}{\partial r_{l}}\left(r_{l}^{2} T_{l} \rho_{l} v_{l}\right)= \\
\frac{1}{C_{p, l} r_{l}^{2}} \frac{\partial}{\partial r_{l}}\left(r_{l}^{2} \lambda_{l} \frac{\partial T_{l}}{\partial r_{l}}\right) \\
+\frac{\rho_{l} D_{l}}{C_{p, l} r_{l}^{2}} \sum_{k}\left[\frac{\partial}{\partial r_{l}}\left(r_{l}^{2} h_{l, k} \frac{\partial Y_{l, k}}{\partial r_{l}}\right)\right. \\
\left.-h_{l, k} \frac{\partial}{\partial r_{l}}\left(r_{l}^{2} \frac{\partial Y_{l, k}}{\partial r_{l}}\right)\right]
\end{gathered}
$$

Here, $\rho_{l}, T_{l}, v_{l}$, and $Y_{l, k}$ are the density, temperature, velocity and mass fraction of species $k$ in the liquid phase, respectively. $D_{l}, \lambda_{l}$, and $h_{l, k}$ are the diffusion constant, thermal conductivity, and enthalpy in the liquid phase, respectively. The specific heat of the liquid mixture at constant pressure, $C_{p, l}$, is defined as:

$$
C_{p, l}=\left.\sum_{k} Y_{l, k} \frac{\partial h_{l, k}}{\partial T_{l}}\right|_{p}=\sum_{k} Y_{l, k}\left(C_{v, l, k}-\frac{p_{l}}{\left(\rho_{l, k}^{o}\right)^{2}} \frac{d \rho_{l, k}^{o}}{d T_{l}}\right)
$$

where $C_{v, l, k}$ is the specific heat at constant volume for the pure species $k$. Here it is assumed that the liquid internal energy and pure fuel species density are functions of temperature alone. The interface condition for the mass fraction of fuel species $k$ is represented by the following equation:

$$
\begin{aligned}
\rho_{l, s}\left(v_{l, s}-\dot{r}_{s}\right)\left(Y_{v, s, k}\right. & \left.-Y_{l, s, k}\right)+\left.\rho_{l, s} D_{l} \frac{\partial Y_{k}}{\partial r}\right|_{l, s} \\
& -\rho_{g, s} D_{g, k} S h_{g, k}\left(\frac{Y_{v, \infty, k}-Y_{v, s, k}}{2 r_{s}}\right)=0
\end{aligned}
$$

Here, $Y_{v, \infty, k}$ is the fuel vapor mass fraction at infinity and $D_{g, k}$ is the diffusion constant of species $k$ in the gas phase. The subscript $s$ denotes the values of the quantities at the liquid-vapor interface. The surface regression rate can be obtained by summing equation (15) over all fuel species as,

$$
\dot{r}_{s}-v_{l, s}=\frac{\rho_{g, s} \sum_{k} D_{g, k} S h_{g, k}\left(Y_{v, \infty, k}-Y_{v, s, k}\right)}{2 \rho_{l, s} r_{s}\left(1-Y_{l, s, f}\right)}
$$

The interface condition for the temperature is imposed through the following equation,

$$
\begin{aligned}
\sum_{k_{f u e l}} L_{v, k, s} \rho_{l, s}\left[\left(\dot{r}_{l, s}-v_{l, s}\right) Y_{l, s, k}\right. & \left.+\left.D_{l} \frac{\partial Y_{k}}{\partial r}\right|_{l, s}\right]-\left.\lambda_{l} \frac{\partial T}{\partial r}\right|_{l, s} \\
& +\lambda_{g, s} N u_{g} \frac{T_{g, \infty}-T_{s}}{2 r_{s}}=0,
\end{aligned}
$$

The effect of internal circulation in the droplet is modeled by using effective thermal conductivity coefficient $\lambda_{l}^{e}$ and mass diffusivity coefficient $D_{l}^{e}$. The expressions for $\lambda_{l}^{e}$ and $D_{l}^{e}$ are derived based on a 2D asymmetric model [48] which assigns the Hill spherical vortex solution to the velocities.

$$
\frac{\lambda_{l}^{e}}{\lambda_{l}}=\frac{D_{l}^{e}}{D_{l}}=1.86+0.86 \tanh \left\{2.245 \log _{10}\left(\frac{\operatorname{Re}_{l} P r_{l}}{30}\right)\right\}
$$

where $R e_{l}=2 U_{s} r_{s} \rho_{l} / \mu_{l}$, and $U_{s}$ is the maximum liquid surface velocity given by

$$
U_{s}=\frac{1}{32}\left|u+u^{\prime}-v\right|\left(\mu_{g} / \mu_{l}\right) \operatorname{Re}_{g} C_{F},
$$

and $C_{F}=12.69 R_{g}^{-2 / 3} /\left(1+B_{d}\right)$ is the friction drag coefficient. The gas phase Nusselt number $N u_{g}$ [1] is obtained from the well-known Ranz-Marshall correlation,

$$
N u_{g}=\left(2.0+0.6 \operatorname{Re}_{g}^{1 / 2} \operatorname{Pr}_{g}^{1 / 3}\right) \frac{\ln \left(1+B_{T}\right)}{B_{T}},
$$

The analogous form of Sherwood number $S h_{g, k}$ [21],

$$
S h_{g, k}=\left(2.0+0.6 R e_{g}^{1 / 2} S c_{g, k}^{1 / 3}\right) \frac{\ln \left(1+B_{d}\right)}{B_{d}},
$$

is used for mass transfer. In equation (21), $B_{T}$ is the Spalding heat transfer number and $B_{d}$ is the Spalding mass transfer number,

$$
\begin{gathered}
B_{T}=\frac{C_{v}\left(\hat{T}-T_{s}\right)}{L_{v, s}-\left(\left|\dot{q}_{d}\right| / \dot{m}_{d}\right)} \\
B_{d}=\frac{Y_{v, s, F}-\sum_{k} Y_{v, \infty, k}}{1-Y_{v, s, F}},
\end{gathered}
$$

Here, $C_{v}$ is the specific heat at constant volume for the fuel vapor mixture, $L_{v, s}$ is the latent heat of evaporation at the droplet surface temperature and $\dot{q}_{d}$ and $\dot{m}_{d}$ are the heat and mass transfer rates, respectively. The gas phase properties are calculated at the temperature $\hat{T}=$ $\left(T_{g_{\infty}}+T_{s}\right) / 3$ using the " $1 / 3$ " rule.

In many multicomponent mixtures, the phase equilibrium solution deviates from the ideal case solution provided by Raoult's law. Here, the Raoult's law for relatively low pressures has been modified by using activity 
coefficients to make it more suitable for real liquids. For this, we use the following equation,

$$
p_{v, k}=\gamma_{k} X_{l, s, k} p_{v a p, k}^{0}
$$

where $p_{v, k}$ is the partial pressure of species $k$ in the gas phase at the droplet surface, $\gamma_{k}$ is the activity coefficient of component $k, X_{l, s, k}$ is the mole fraction of species $k$ in the liquid phase at the droplet surface, and $p_{v a p, k}^{0}$ is the equilibrium vapor pressure for a pure species $k$ at the surface temperature $T_{s}$. The parameter $\gamma_{k}$ is calculated using the UNIFAC method $[49,50]$. The surface mole fraction at the liquid phase and the surface mass fraction in the gas phase can be obtained from the following equations.

$$
\begin{gathered}
X_{l, s, k}=\frac{Y_{l, s, k} / W_{k}}{\sum_{j} Y_{l, s, j} / W_{j}}, \\
Y_{v, s, k}=\frac{X_{v, s, k} W_{k}}{\sum_{j} X_{v, s, j} W_{j}}=\frac{p_{v, k} W_{k}}{\sum_{j} p_{g, s, j} W_{j}}
\end{gathered}
$$

The internal linear equations (11) - (13) and the nonlinear interface equations (15) - (17) are solved simultaneously by decoupling them using matrix manipulation. An implicit finite volume scheme is used to discretize the conservation equations and the non-linear interfacial constraints are implemented through Broyden's method. Broyden's method is an extension of the secant method developed for solving systems of non-linear equations. In this method, an approximate Jacobian is used to update the multidimensional solution as described in detail by Dennis et al. [51]. The particle location and velocity are obtained by solving equations (1) and (2), respectively. The thermo-physical properties, including surface tension, are a function of temperature and are calculated using suitable correlations and methods given in Poling et al. [52]

\subsection{Gas Phase equations}

As mentioned before, a hybrid Eulerian-Lagrangian mathematical computational method is used in this work for the solution of liquid-gas system. The (Lagrangian) liquid drop equations are the focus in this work and are described in details above. For the gas phase, the filtered form of compressible Navier-Stokes, energy and scalar equations are solved in LES with gradient type SGS models. These equations and the numerical method used for their solution are described in details in References $[53,54]$ and are not presented here.

\section{Results and Discussion}

The multicomponent evaporation model described in the previous section has been incorporated into the spray and LES simulators and has been used for the simulations of single-component and multicomponent evaporating fuel sprays in Sandia's experimental closed vessel configuration [62]. However, before analyzing the LES/spray data, it is necessary to assess the multicomponent droplet solver and its finite rate heat and mass transfer models below by comparing its predictions with those obtained with much simpler singlecomponent droplet heat and mass transfer model, referred to as the "lumped" model in this paper.

\subsection{Single droplet calculations}

The single droplet calculations have been carried out for both single component and multicomponent liquids. The single component simulations demonstrate the differences between the lumped and multicomponent models and allow us to isolate and to study various subcomponents of the multicomponent model.

\subsubsection{Single component liquid}

Simulations have been carried out for a singlecomponent n-hexadecane fuel with both the multicomponent evaporation model and the single component "lumped" evaporation model, under the same operating conditions at gas temperature and pressure of 700 $\mathrm{K}$ and $1 \mathrm{~atm}$, respectively. In both simulations, the nhexadecane droplets are released with temperature of $293 \mathrm{~K}$ into a gas chamber. The multicomponent model is capable of utilizing fully variable physical properties for the fuel. However, in order to compare the results of the multicomponent model with the simpler lumped model, constant physical properties, evaluated at the average temperature of the droplet, have been used. Also, the liquid velocity inside the droplet is not considered and the liquid thermal conductivity is increased artificially to very high values to simulate infinite thermal conductivity and mass diffusivity conditions in the lumped model. With these additional features of the multicomponent model turned off, the results obtained from these two models should be similar. Figure 1(a) shows the time variation of the bulk droplet temperature for the multicomponent and lumped models. Both models predict similar behavior for the droplet temperature during the heating period due to high thermal conductivity used in the multicomponent model, and the similarity of liquid properties. As the droplet temperature increases and evaporation starts at the droplet surface, the average droplet temperature remains nearly constant. Nevertheless, the results obtained by the multicomponent model remain very close to those predicted by the lumped model for the simulated limiting conditions. Figure 1(b) shows the time variation of the droplet 
area (or $D^{2}$ ), normalized by the initial area, for a droplet with initial diameter of $20 \mu \mathrm{m}$. Again, both models predict a similar rate of evaporation and as expected for single-component droplets, both models predict a "Dsquare" law behavior, i.e. the square of droplet diameter decreases linearly in time after the initial heating period. This confirms that the multicomponent model's predictions match with the lumped model's predictions in the limiting conditions, even though the mathematical and computational methods used in them are quite different.

In order to study the effect of various liquid fuel properties on the droplet evaporation, the fuel properties were systematically changed with respect to the base line model (multicomponent model with constant properties) shown in Figure 1. Figure 2 shows the effect of liquid thermal conductivity, heat capacity coefficient, and latent heat of vaporization on the droplet lifetime and bulk temperature. When finite thermal conductivity is considered, there is a slight increase in the droplet lifetime (Figure 2(a)). This increase in lifetime can be attributed to the slower rate of heating and lower temperatures during the heating phase of the droplet, as seen in Figure 2(b). As shown in Figure 2(a), variable liquid specific heat causes a much faster evaporation rate due to the lower specific heat at lower drop temperatures, Consequently a higher drop temperature is achieved in the heating phase of the liquid droplet as seen in Figure 2(b). The effect of variable liquid density on the droplet heating and evaporation is shown in Figure 3(a). The thermal expansion of the fuel droplet caused by the decrease in liquid density of the fuel during the droplet heating phase is well captured by the model, even though there is no significant change in droplet lifetime. The constant density model fails to capture the thermal expansion of the droplet. The difference between constant and variable property results is also evident in Figures 3(a) and 3(b), where the time variations of the normalized droplet area and temperature, respectively, are shown for droplets with constant properties and fully variable properties. It is clear that the droplet evaporates at a faster rate and has a higher temperature than the baseline, constant property droplet. The effect of all the properties being variable is significant and illustrates the importance of using variable properties in droplet evaporation models. The variable property droplet also has a slightly higher final temperature. Using the variable property multicomponent evaporation model, a systematic study is carried out to examine the effect of changing various fuel properties from their "reference" (actual) values. Keeping all the other properties at their reference values and the gas proper- ties constant, one of the considered properties is varied from its baseline values to simulate fuels with concomitant properties. For instance, Figures 4 - 5 show the effects of the liquid density and latent heat of vaporization on the droplet heating, evaporation, lifetime and bulk temperature. It is shown in Figure 4(a) that by decreasing the liquid density (while keeping the initial droplet size the same), the droplet lifetime decreases simply because the droplet mass is changing. During the heating phase, the droplet bulk temperature increases by decreasing the liquid density (Figure 4(b)). This is due to the lower energy required to heat lesser amount of fuel. Figures 5(a) and 5(b) show that decreasing the latent heat of vaporization decreases the droplet lifetime, while the maximum droplet bulk temperature increases. This is due to the corresponding decrease in the energy required for the evaporation. Increasing the liquid thermal conductivity has no significant effect on the droplet lifetime and bulk temperature (not shown here).

\subsubsection{Multicomponent liquid}

To assess the true performance of the multicomponent model for real fuels, an attempt is made in this section to simulate the evaporation of Diesel 2 fuel. Diesel2 is a chemically complex multicomponent mixture with a wide distillation character. In order to reduce the chemical and physical complexity of the diesel fuel, surrogate fuels have often been used in studies focusing on deeper understanding of processes involved in diesel fuel vaporization, mixing and combustion. Some of the diesel surrogate fuels which have been used in previous studies are presented in Table 1. Four of these mixtures have been used as surrogates for the simulation of the physical behavior of diesel in this paper, namely the bi-component mixture of n-decane $\left(\mathrm{C}_{10} \mathrm{H}_{22}\right)$ and $\alpha$ - methylnaphthalene $\left(C_{11} H_{10}\right)$, the 6-species mixture of 5 n-alkanes and 1 aromatic compound [24], and the 8 species surrogates CFA and FD9A developed by Mueller et al.[66]. Here, CFA is the acronym for a 2007 \#2 ULSD certification fuel from ChevronPhillips Chemical Co., while FD9A stands for Fuels for Advanced Combustion Engines (FACE) Diesel\#9 Batch A. The 8 species surrogates were created by optimizing the compositions using a multi-property regression algorithm to match the known carbon bond types and ignition qualities and volatilities of the target fuels and comprise of all the major hydrocarbon classes found in the target fuels, viz. n-alkanes, iso-alkanes, mono- and dicycloalkanes; mono- and diaromatics; and naphtho-aromatics. In order to evaluate the effect of non-idealities of the liquid phase on the evaporation process, the computational results for the evaporation of 


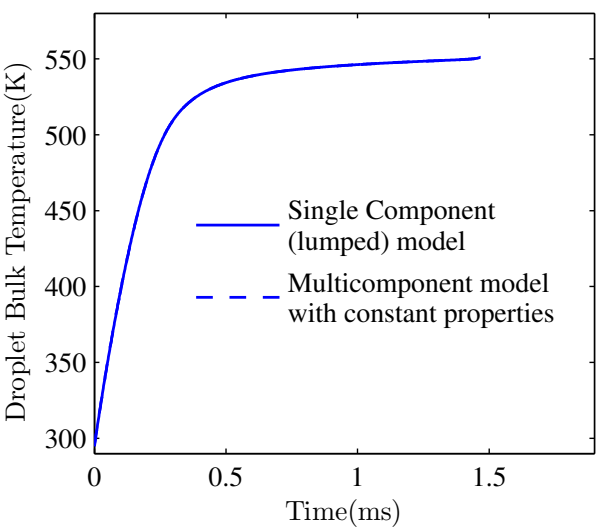

(a)

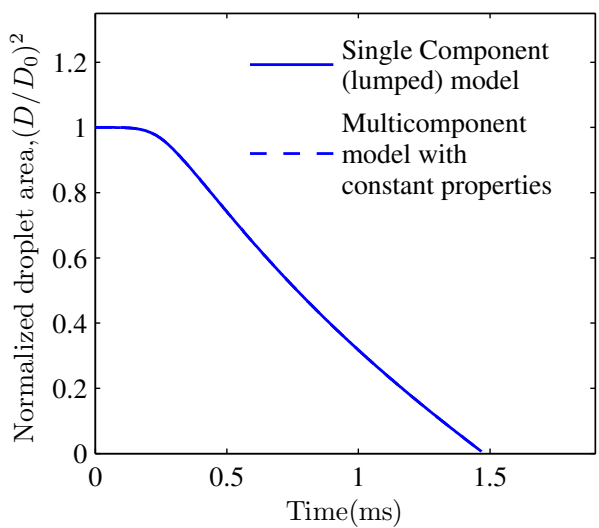

(b)

Figure 1: Variation of Droplet (a) temperature, and (b) area, with time. Initial Droplet Diameter $=20 \mu m$, Initial Droplet Temperature $=293 \mathrm{~K}$, Initial Gas Temperature $=700 \mathrm{~K}$, Gas Pressure $=1 \mathrm{~atm}$, Boiling Point of n-hexadecane at $1 \mathrm{~atm} .=560 \mathrm{~K}$.

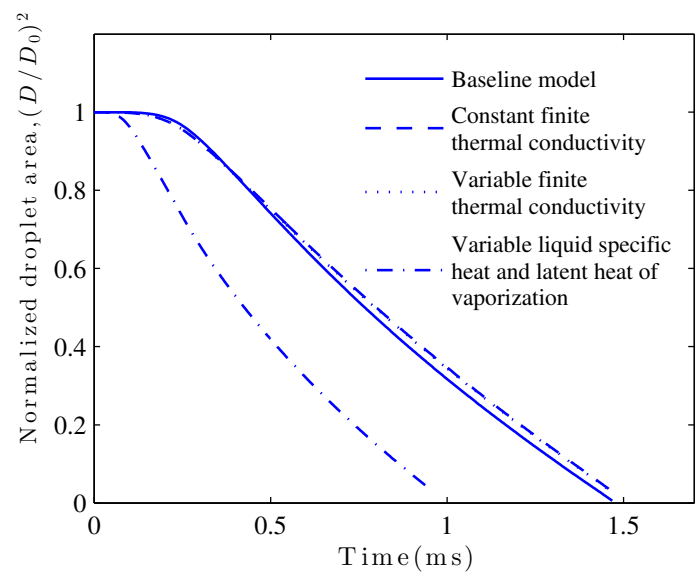

(a)

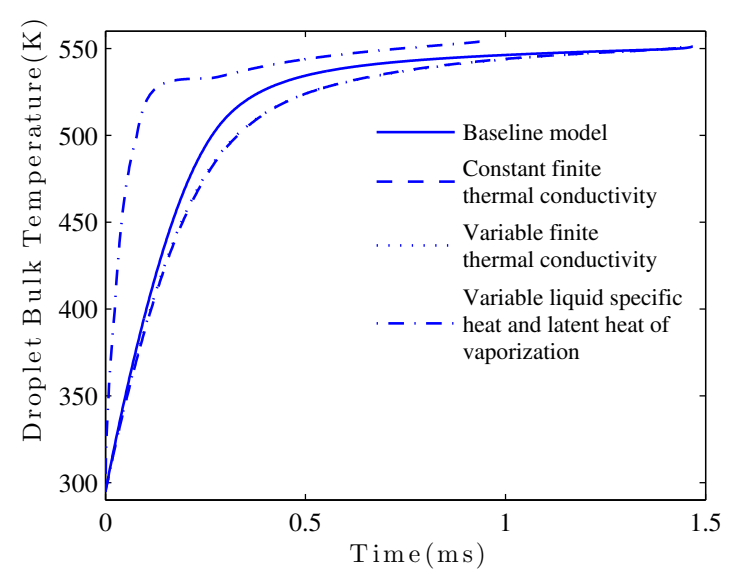

(b)

Figure 2: Effect of finite thermal conductivity and variable liquid specific heat and latent heat of vaporization on droplet (a) area, and (b) temperature.

a droplet of $70 \%$ n-decane and $30 \% \alpha$ - methylnaphthalene (by volume) for ideal and non-ideal models are compared. In the ideal case, the activity coefficient in equation (24) is set to $\gamma_{k}=1$. Figure 6 shows the temporal variations of the droplet area and bulk temperature. Changes in the droplet lifetime and maximum temperature are insignificant but there is a slight decrease in the evaporation rate when the non-ideal model is used. There is also a slight increase in the droplet temperature at intermediate times (which accounts for the increase in the evaporation rate at later stages), resulting in a negligible net change in the droplet lifetime. However, there are significant differences in the liquid fuel species composition as seen in the mass frac- tion profiles in Figure 7. The rate of evaporation of the more volatile component $\mathrm{n}$-decane is adversely affected due to the presence of a less volatile $\alpha$ - methylnaphthalene when their mutual interaction viz. non-ideal effects are considered. This effect is important to the fuel-vapor distribution in the gas phase and exemplifies the significance of considering the real liquid effects on the fuel evaporation. The evaporation of a single drop of the 6-species diesel surrogate is simulated to gain an understanding of the behavior of more complex multicomponent fuels. Figure 8 shows the evolution of the average species mass fractions for the whole droplet in time and the mass fraction profiles inside the droplet at a particular time. The most volatile compo- 


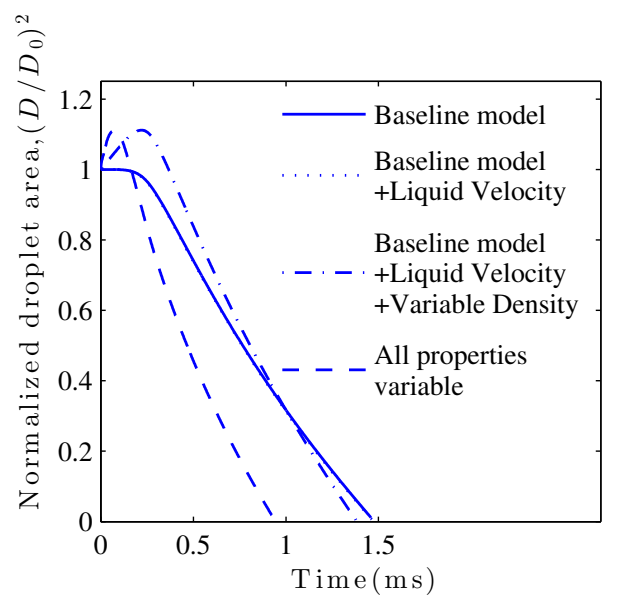

(a)

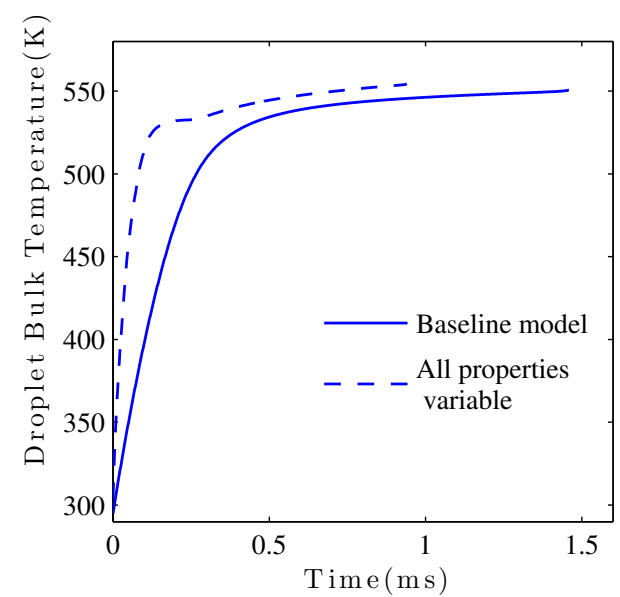

(b)

Figure 3: (a) Effect of liquid velocity, variable liquid density and all properties variable on droplet area, (b) Effect of variable properties on droplet temperature.

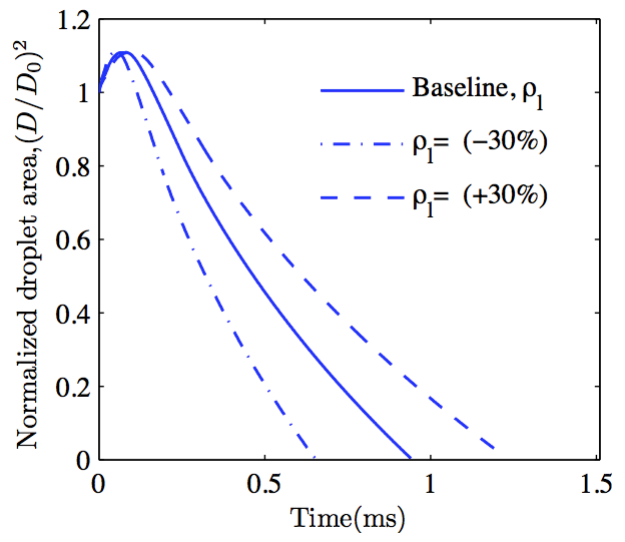

(a)

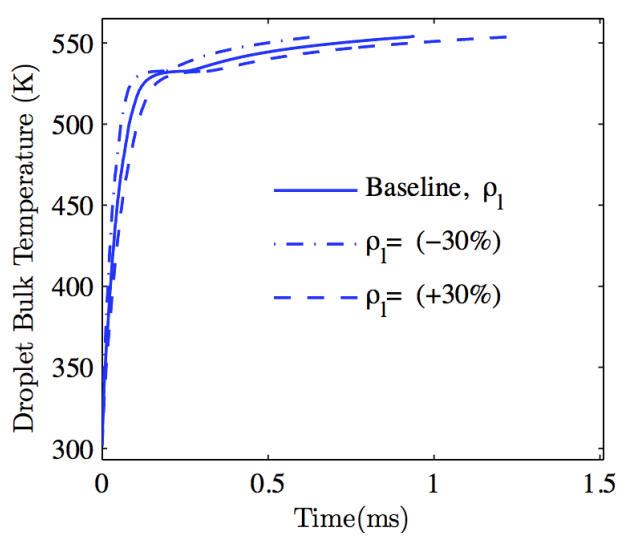

(b)

Figure 4: Time variation of (a) droplet area, and (b) droplet bulk temperature for different values of the liquid density, $\rho_{l}$.

nent, toluene $\left(\mathrm{C}_{7} \mathrm{H}_{8}\right)$, evaporates first as expected and as can be seen in Figure 8(a). As the drop temperature increases, the heavier species evaporate too. At the end of its lifetime, the droplet is mostly composed of the heaviest and least volatile species, n-octadecane $\left(\mathrm{C}_{18} \mathrm{H}_{38}\right)$. Figure $8(\mathrm{~b})$ shows the mass fraction profiles in the droplet interior at the initial stages of the evaporation process. The evaporation starts at the surface, with the most volatile fuel evaporating first, resulting in the creation of nonuniform inner droplet distribution, which are captured well by the multicomponent model. The multi-component evaporation model developed here can be applied to study the behavior of different fuels including biofuels. Single drop studies have been carried out to characterize the behavior of blends of Methyl Oleate (MO, Canola Biodiesel, $\mathrm{C}_{19} \mathrm{H}_{36} \mathrm{O}_{2}$ ), Dibutyl Succinate (DBS, $\mathrm{C}_{12} \mathrm{H}_{22} \mathrm{O}_{4}$ ), 2-ethylhexyl nonanoate (2-EHN, $\mathrm{C}_{17} \mathrm{H}_{34} \mathrm{O}_{2}$ ), Butyl nonanoate (BN, $\mathrm{C}_{13} \mathrm{H}_{26} \mathrm{O}_{2}$ ), isobutyl nonanoate (iBN, $\mathrm{C}_{13} \mathrm{H}_{26} \mathrm{O}_{2}$ ), 2-ethylhexyl butyrate (2-EHB, $\mathrm{C}_{12} \mathrm{H}_{24} \mathrm{O}_{2}$ ) and a Diesel surrogate (cetane, n-hexadecane, $\mathrm{C}_{16} \mathrm{H}_{34}$ ). The physical properties of these components have been calculated using suitable correlations and methods given in Poling et al. [52]. Methyl Oleate has the highest liquid specific heat and latent heat of vaporization and the lowest vapor pressure and thermal conductivity at lower temperatures. This implies that a higher concentration of Methyl Oleate would require higher heat input for droplet heat- 


\begin{tabular}{|c|c|}
\hline \multicolumn{2}{|r|}{ Diesel Fuel Surrogates } \\
\hline 2 species & D2N: 70\% n-decane $\left(C_{10} H_{22}\right)+30 \% \alpha-$ methylnaphthalene $\left(C_{11} H_{10}\right)$ by volume [63] \\
\hline 6 species & $\begin{array}{l}\text { D6N: } 16 \% \text { toluene }\left(C_{7} H_{8}\right)+14 \% \text { n-decane }\left(C_{10} H_{22}\right)+22 \% \text { n-dodecane }\left(C_{12} H_{26}\right)+24 \% \text { n-tetradecane }\left(C_{14} H_{30}\right) \\
+13 \% \text { n-hexadecane }\left(C_{16} H_{34}\right)+11 \% \text { n-octadecane }\left(C_{18} H_{38}\right) \text { by mole fraction [24] }\end{array}$ \\
\hline 8 species & $\begin{array}{l}\text { CFA 20.2\% n-octadecane }\left(\mathrm{C}_{18} \mathrm{H}_{38}\right)+2.7 \% \text { n-hexadecane }\left(\mathrm{C}_{16} \mathrm{H}_{34}\right)+29.2 \% \text { 2,2,4,4,6,8,8-heptamethylnonane } \\
\left(\mathrm{C}_{16} \mathrm{H}_{34}\right)+5.1 \% \text { n-butylcyclohexane }\left(\mathrm{C}_{10} \mathrm{H}_{20}\right)+5.5 \% \text { trans-decalin }\left(\mathrm{C}_{10} \mathrm{H}_{18}\right)+7.5 \% 1,2,4 \text {-trimethylbenzene } \\
\left(\mathrm{C}_{9} \mathrm{H}_{12}\right)+15.4 \% \text { tetralin }\left(\mathrm{C}_{10} \mathrm{H}_{12}\right)+14.4 \% \text { 1-methylnaphthalene }\left(\mathrm{C}_{11} \mathrm{H}_{10}\right) \text { by mole fraction [66] } \\
\text { FD9A 7.8\% n-eicosane }\left(\mathrm{C}_{20} \mathrm{H}_{42}\right)+13.1 \% \text { n-octadecane }\left(\mathrm{C}_{18} \mathrm{H}_{38}\right)+28.2 \% 2,2,4,4,6,8,8 \text {-heptamethylnonane } \\
\left(\mathrm{C}_{16} \mathrm{H}_{34}\right)+5.0 \% \text { n-butylcyclohexane }\left(\mathrm{C}_{10} \mathrm{H}_{20}\right)+10.0 \% \text { trans-decalin }\left(\mathrm{C}_{10} \mathrm{H}_{18}\right)+18.8 \% \text { 1,2,4-trimethylbenzene } \\
\left(\mathrm{C}_{9} \mathrm{H}_{12}\right)+11.3 \% \text { tetralin }\left(\mathrm{C}_{10} \mathrm{H}_{12}\right)+5.8 \% \text {-methylnaphthalene }\left(\mathrm{C}_{11} \mathrm{H}_{10}\right) \text { by mole fraction [66] }\end{array}$ \\
\hline
\end{tabular}

Table 1: Multicomponent surrogate fuels used for simulation of Diesel

ing and evaporation. On the contrary, 2-EHB lies at the other end of the spectrum with the lowest liquid specific heat and latent heat of vaporization and the highest vapor pressure and is the most volatile of the components considered here. BN and iBN have properties similar to 2-EHB and similar results can be expected for fuels containing these species. The specific heat and vapor pressure of 2-EHN are closer to Methyl Oleate as compared to other components and its volatility should be similar too. DBS has intermediate properties but its density is the highest. Consequently, droplets with DBS would take longer to evaporate due to their higher mass. In order to understand the heat and mass transfer characteristics of the bio-fuel components, a set of simulations consisting of stationary droplets, suspended in a stagnant environment is considered. The droplets are composed of two components, with Methyl Oleate as the base fuel and a second component. The initial droplet size and temperature are $50 \mu m$ and $400 \mathrm{~K}$, re- spectively. The gas pressure and temperature are $1 \mathrm{~atm}$ and $700 \mathrm{~K}$, respectively. Figure 9 shows the droplet lifetimes for stationary droplets of bi-component biofuel blends. As expected, the shortest droplet lifetimes are for bi-component droplets with 2-EHB due to its higher volatility. Since Methyl Oleate is the least volatile of all the species considered, the droplet lifetimes decrease as the mass fraction of the second, more volatile component, is increased. The longest droplet lifetimes are for Methyl Oleate +2 -EHN droplets, especially when the mass fraction of 2-EHN is higher. This is due to the low vapor pressure and higher latent heat of vaporization of these droplets. The droplet lifetimes for BN and iBN are similar and relatively higher than 2-EHB. Although $\mathrm{n}$-hexadecane is the lightest of the species considered here, it is less volatile than 2-EHB, BN and iBN and consequently its lifetime is higher.

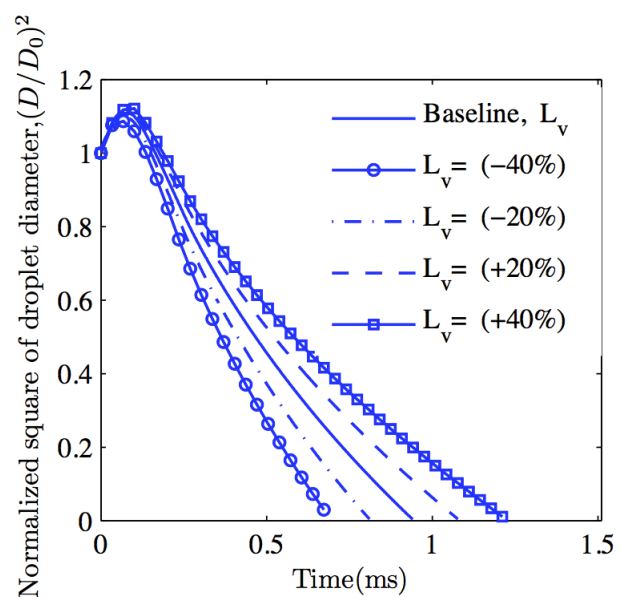

(a)

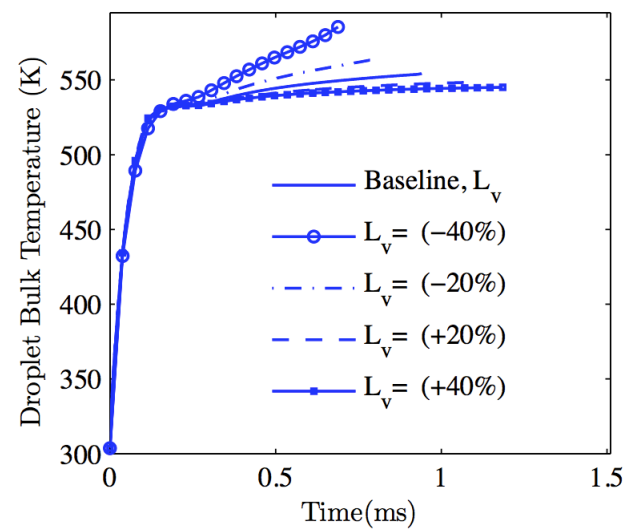

(b)

Figure 5: Time variation of (a) droplet area, and (b) droplet bulk temperature for different values of the latent heat of vaporization, $L_{v}$. 


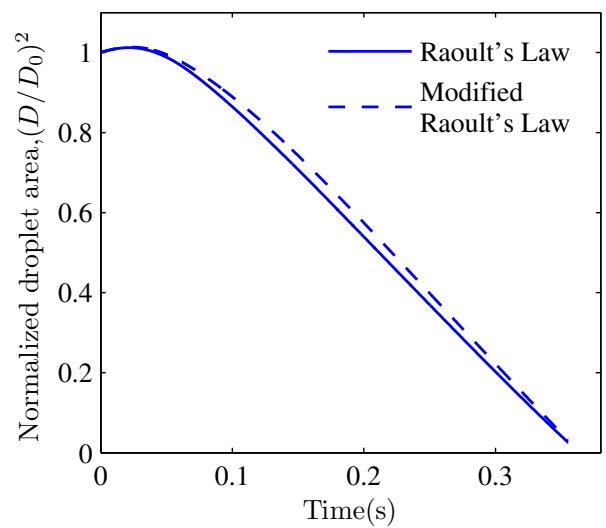

(a)

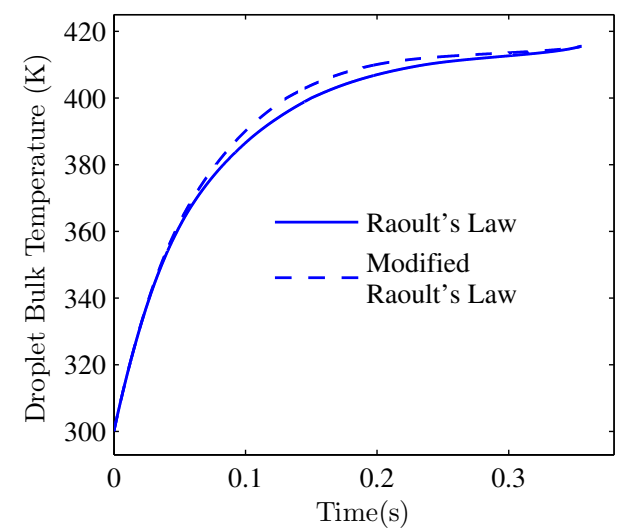

(b)

Figure 6: Variation of (a) droplet area, (b) droplet temperature, with time for a fuel with composition $61 \%$ decane $+39 \% \alpha$-methylnaphthalene (by mass) and initial droplet diameter $=200 \mu \mathrm{m}$, gas temperature $=550 \mathrm{~K}$, gas pressure $=1.01325 \mathrm{e}+05 \mathrm{~N} / \mathrm{m}^{2}$.

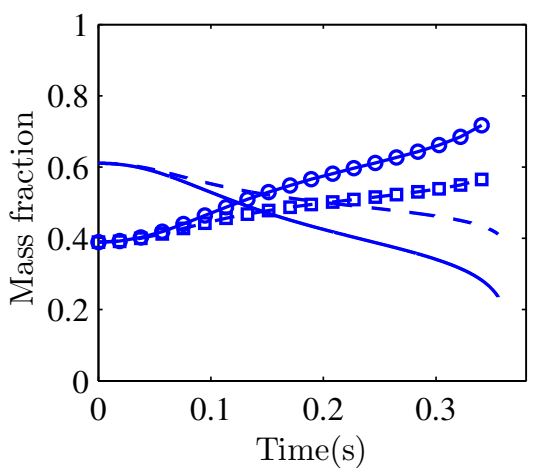

(a)

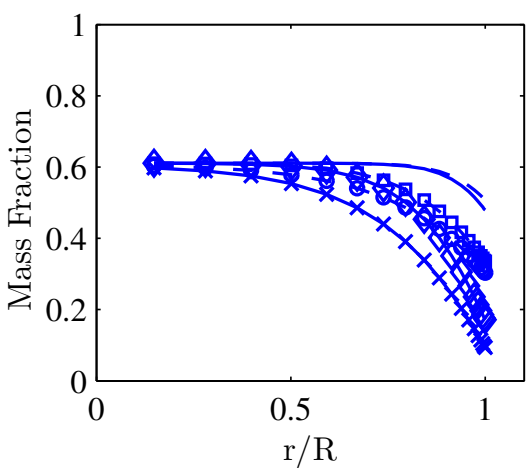

(b)

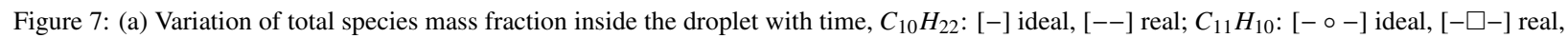
(b) Mass fraction profiles of $\mathrm{n}$-decane inside the droplet at different times, $[-] \mathrm{t}=0.05 \mathrm{~s}$ (ideal liquid); [--] $\mathrm{t}=0.05 \mathrm{~s}$ (real liquid); $[-\diamond-] \mathrm{t}=0.15 \mathrm{~s}$ (ideal liquid); [- $\square--] \mathrm{t}=0.15 \mathrm{~s}$ (real liquid); $[-\times-] \mathrm{t}=0.25 \mathrm{~s}$ (ideal liquid); [- $-\circ--] \mathrm{t}=0.25 \mathrm{~s}$ (real liquid).

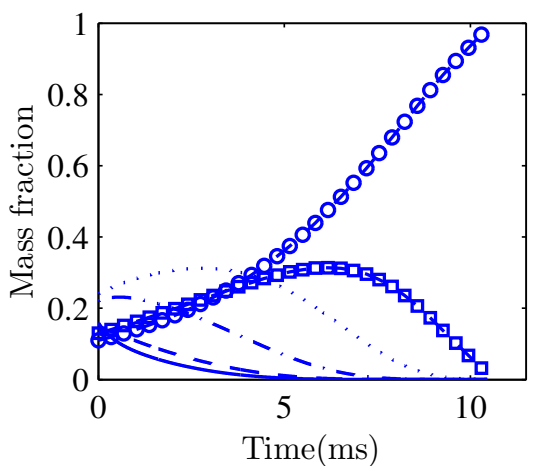

(a)

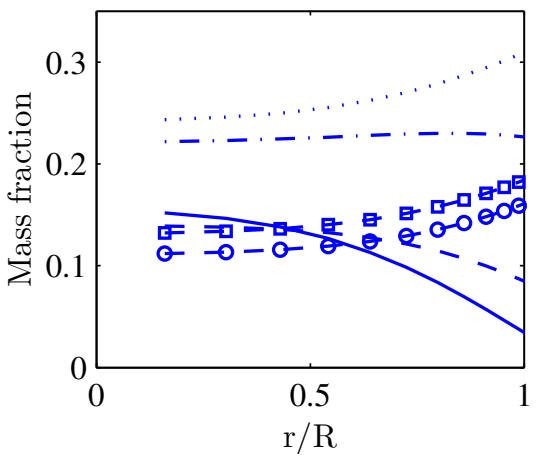

(b)

Figure 8: (a) Variation of average species mass fraction inside droplet with time for a six-component diesel surrogate, (b) Mass fraction profiles of fuel components inside the droplet during the evaporation process. [-] $\mathrm{C}_{7} \mathrm{H}_{8} ;[--] \mathrm{C}_{10} \mathrm{H}_{22} ;[-.] \mathrm{C}_{12} \mathrm{H}_{26} ;[\ldots.] \mathrm{C}_{14} \mathrm{H}_{30} ;[-\square-] \mathrm{C}_{16} \mathrm{H}_{34} ;[-\circ-]$ $\mathrm{C}_{18} \mathrm{H}_{38}$. 


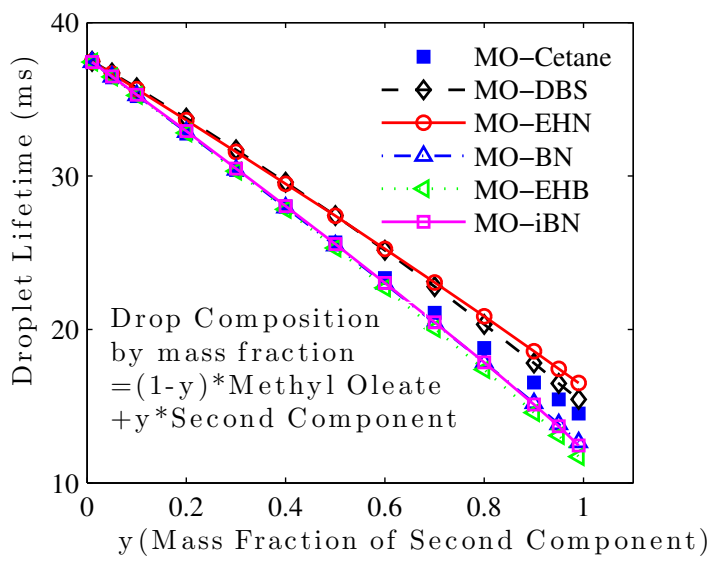

Figure 9: Lifetimes for Biofuel and Biodiesel Blend droplets suspended in stagnant air at atmospheric pressure and $700 \mathrm{~K}$. Initial Droplet Temperature $=400 \mathrm{~K}$. Initial Droplet Diameter $=50 \mu \mathrm{m}$.

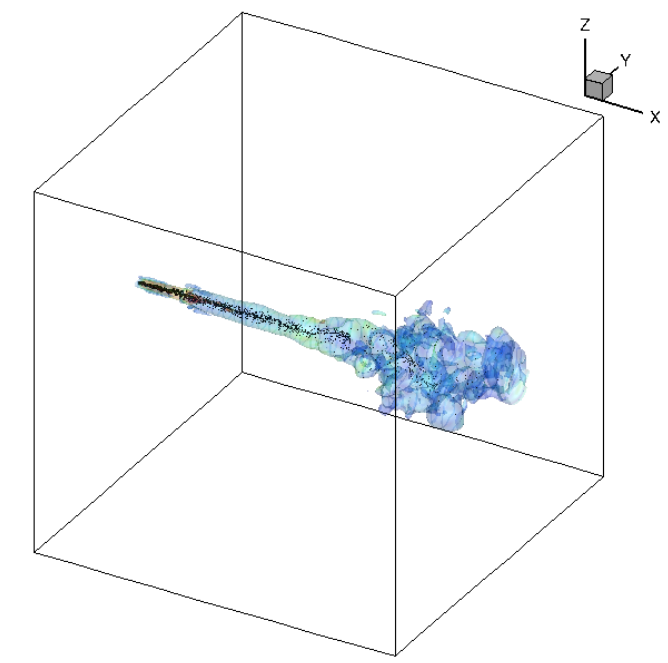

Figure 10: LES domain with spray and iso-surfaces of gas temperature.

\subsection{Spray simulations}

The variable property multicomponent model has been used together with our hybrid Eulerian-Lagrangian LES/spray model to simulate spray experiments performed at Sandia National Laboratory [62]. The experimental setup consisted of an optically accessible constant-volume cubical combustion vessel with a characteristic dimension of $108 \mathrm{~mm}$. The fuel is injected through a high-pressure injection system and is visualized using the Mie-scattering technique. The spray "length" or the maximum axial penetration distance of the liquid fuel is obtained from the time averaged Mie scattered images by determining the maximum axial distance of the droplets with a light intensity above a selected threshold [62]. The experiments were repeated for n-hexadecane, Diesel2, and other fuels and for ambient gas temperature of 700-1300 K, ambient gas pressure of $3.6-58.5 \mathrm{~kg} / \mathrm{m}^{3}$, injection pressures of $41-172$ $\mathrm{MPa}$, and nozzle diameters of 0.1-0.498 mm. The computational domain used in the simulations is shown in Figure 10.

Some of the most important processes affecting the evaporation and mixing of liquid fuels are the primary and secondary breakup of the liquid jet and droplets, and the droplet transport, collision, coalescence, and evaporation. Models affecting the prediction of spray length include those used for the droplet drag, heat and mass transfer and breakup process. Here, the spray has been numerically simulated using the "blob" model in which mono-disperse particles are injected into the 
computational domain with particle size equal to the effective diameter of the nozzle orifice. The injected blobs undergo secondary breakup subject to the combined KH-RT model [68], [69], which is a competitive implementation of the Kelvin-Helmholtz $(\mathrm{KH})$ and Rayleigh-Taylor (RT) models. Unstable waves grow on the droplet surface due to aerodynamic forces caused by the relative velocity between the liquid and gas phases. In the KH model, new child droplets, with sizes proportional to the wavelength of the fastest growing and most unstable waves on the droplet surface, are stripped off the parent droplet. The implementation of the KH-RT models requires two adjustable parameters $B_{1}$ and $C_{R T}$ based on the nozzle geometry and initial conditions of the spray. The parameter $B_{1}$ determines the length $L_{b}$ of the dense fragmented core, while the parameter $C_{R T}$ controls the size of the daughter droplets after the RT breakup. In the near nozzle dense region, the droplets are tightly packed and it can be expected that a large number of them are in the wake region of other droplets preceding them. This implies that they do not"see" the effect of the surrounding air completely. In the absence of a comprehensive model to predict the droplet wake and the effect of nearby droplets on the droplet heat and mass transfer, semi-empirical correlations for the Nusselt and Sherwood numbers are used in this study with some corrections for high speed droplets. Also, the multicomponent evaporation model is currently unable to fully consider high pressure, trans-critical and supercritical conditions and deviations from experimental results can be expected under some extreme conditions.

\subsubsection{Single component liquid sprays}

One of the important global spray parameters, characterizing the effectiveness of spray breakup and evaporation is the liquid penetration length or the spray length. The numerical spray length is defined as the axial location before which most of the liquid jet mass is located. Since the experimental definition of the spray length is based on a threshold of light intensity and cannot be directly converted into an exact percentage of liquid penetration, this length has been defined differently in literature. Beale et al. [69] defined the penetration length as the location of the $3 \%$ liquid volume contour at the edge of the spray, while Ricart et al. [70] used both $90 \%$ of the liquid mass and the location of the farthest droplet from the nozzle, as the definition of penetration length. Som [71] used the axial location of $97 \%$ of the injected mass as the penetration length. Figure 11(a) compares the liquid lengths obtained for $95 \%$, $97 \%$ and $99 \%$ penetration of the liquid mass for a gas temperature of $700 \mathrm{~K}$ by our LES/spray model. The penetration length predicted by the $97 \%$ criteria yields the best overall match with the experimental results for this particular temperature. The parametric nature of the breakup model necessitates the study of the effect of different breakup parameters on the spray quantities like liquid penetration length. Figure 11(b) shows the effect of the $\mathrm{KH}$ model constant $B_{1}$, which controls the breakup length or the dense core of the liquid jet, with the RT breakup constant $C_{R T}$ fixed at 0.1 . The gas temperature is $700 \mathrm{~K}$. The predicted liquid length increases as $B_{1}$ is increased due to the onset of Rayleigh-Taylor breakup at a later axial location. The numerical results match well for $B_{1}=40$ for all cases except at the gas density of $58.5 \mathrm{~kg} / \mathrm{m}^{3}$. For $B_{1}$ values lower than 20 , the liquid jet never reaches a steady state condition and keeps on penetrating axially. Figure 11(c) shows the effect of the RT breakup constant $C_{R T}$, on the penetration length for a gas temperature of $700 \mathrm{~K}$ and constant $B_{1}$ value of 40 . $C_{R T}$ determines the droplet size after RT breakup; hence a larger value of $C_{R T}$ yields bigger daughter droplets, which take longer to evaporate, leading to a longer penetration length. This trend can be clearly observed in Figure 11(c). For $C_{R T}=0.06$, the liquid jet does not reach a steady state condition at lower gas densities. Apparently, the numerical results match well with the experimental results for a $C_{R T}$ value of 0.10. Based on the results in Figure 11(b) and 11(c), the breakup constants $B_{1}=40$ and $C_{R T}=0.10$ are expected to give the best match between experimental and numerical results for n-hexadecane. Figure 11(d) shows the comparison between experimental and numerical results for gas temperatures of 700-1150 K and gas densities of $3.6-58.5 \mathrm{~kg} / \mathrm{m}^{3}$. The experimental trends of decreasing penetration length with increasing temperature and pressure seem to be captured well by the LES/spray model. The numerical results compare well with the experimental results at gas densities of $3.6 \mathrm{~kg} / \mathrm{m}^{3}$ and $7.3 \mathrm{~kg} / \mathrm{m}^{3}$ at all gas temperatures. The results at gas density of $14.8 \mathrm{~kg} / \mathrm{m}^{3}$ also match well at lower temperatures with a slight over-prediction at $1150 \mathrm{~K}$. As the gas temperature and density are increased, there are slight deviations from the experimental results. The liquid length at gas density of $30.0 \mathrm{~kg} / \mathrm{m}^{3}$ is predicted reasonably well for lower gas temperatures of 700 and $850 \mathrm{~K}$, however at higher temperatures there is an overprediction of the spray penetration length. The penetration length at gas density of $58.5 \mathrm{~kg} / \mathrm{m}^{3}$ is also overpredicted at all temperatures. There can be several possible reasons for the over-prediction of numerical results at high gas temperatures and pressures. For gas temperatures of $1000 \mathrm{~K}$ and $1150 \mathrm{~K}$ with ambient gas density $30.0 \mathrm{~kg} / \mathrm{m}^{3}$ or $58.5 \mathrm{~kg} / \mathrm{m}^{3}$, the breakup length of the 


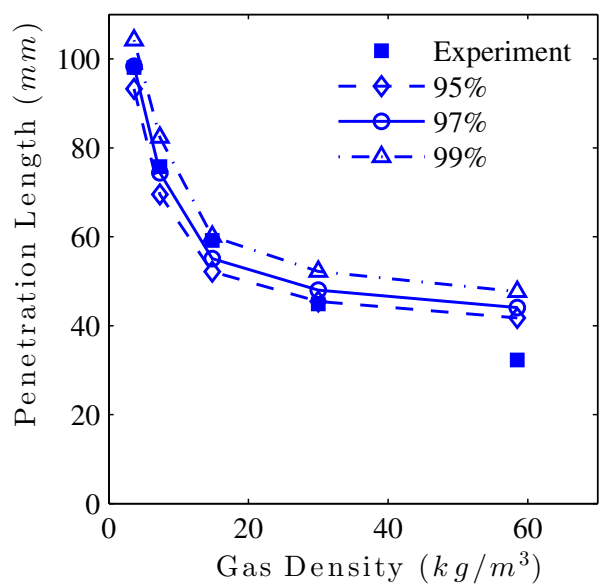

(a)

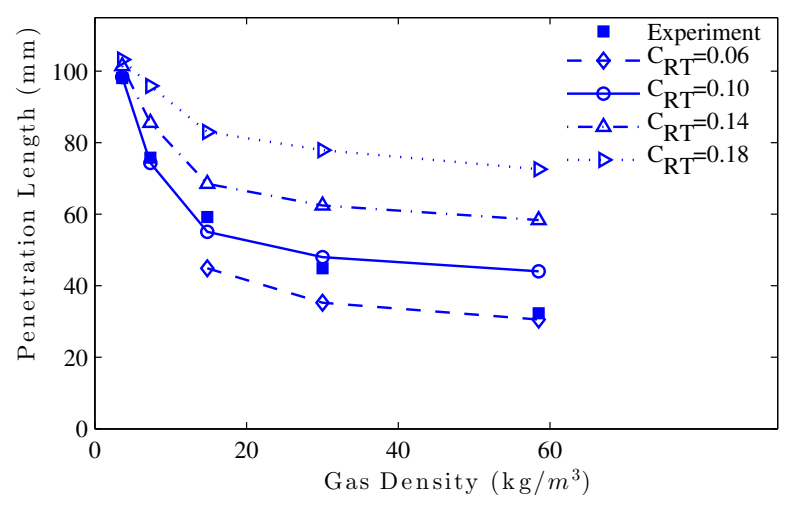

(c)

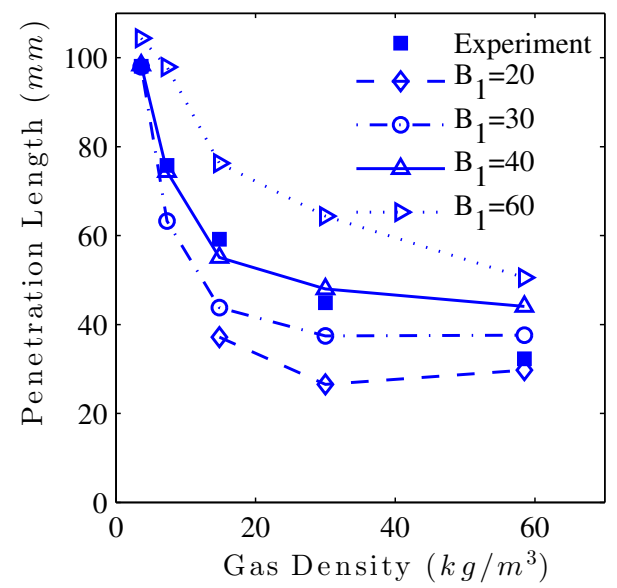

(b)

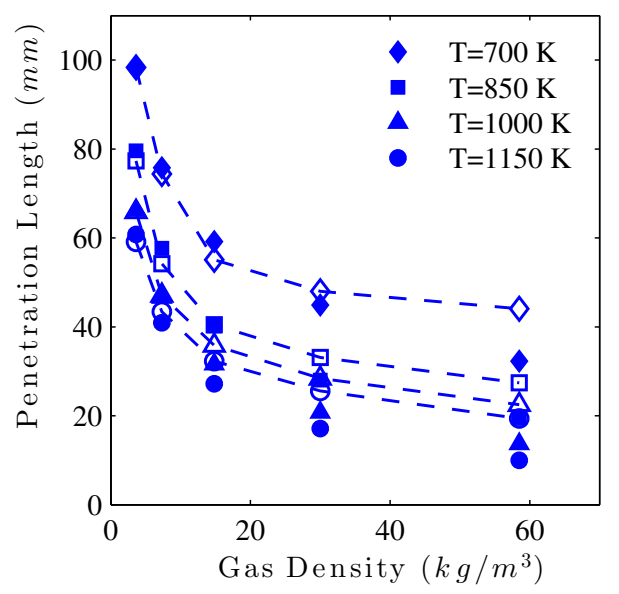

(d)

Figure 11: Liquid penetration length for gas temperature of $700 \mathrm{~K}$ (a) based on penetration of $95 \%$, $97 \%$ and $99 \%$ of the liquid mass., (b) for different values of the $\mathrm{KH}$ breakup constant, $B_{1}, C_{R T}=0.10$, (c) for different values of the RT breakup constant, $C_{R T}, B_{1}=40$. (d) Liquid penetration length for different gas temperatures and densities, $B_{1}=40, C_{R T}=0.10$. The solid and hollow symbols represent the experimental and numerical results, respectively. Fuel: n-hexadecane.

dense fragment core is nearly equal to or greater than the experimental penetration length. This implies that the RT breakup, and consequently the evaporation of the smaller droplets, starts only after the liquid droplets are near or have crossed the axial location of the experimental penetration length, leading to over-prediction of the penetration length for these cases. The over-prediction at higher gas densities (e.g. $30.0 \mathrm{~kg} / \mathrm{m}^{3}$ and $58.5 \mathrm{~kg} / \mathrm{m}^{3}$ ) can also be explained by the gas conditions being supercritical for n-hexadecane and the possibility of the droplet surface reaching supercritical condition, which the current evaporation model is not designed to handle. Heat and mass transfer under supercritical conditions is not clearly understood and is an active area of research. Recent findings in Dahms et al. [72] indicate that under supercritical pressures and high temperatures, the discontinuous gas-liquid interface found at lower temperatures does not exist and a continuous gasliquid interfacial diffusion layer is found instead. Thus, instead of undergoing subcritical processes like primary and secondary breakup, injected jets experience a continuous change of state. The Lagrangian particle approach for modeling spray is thus not applicable under such conditions. Some progress has been made in understanding the transition from the discontinuous interface to the continuous diffusion layer using Linear Gradient Theory [72]. Note that for the gas pressure and temperature of $58.5 \mathrm{~kg} / \mathrm{m}^{3}$ and $1150 \mathrm{~K}$, the reduced 


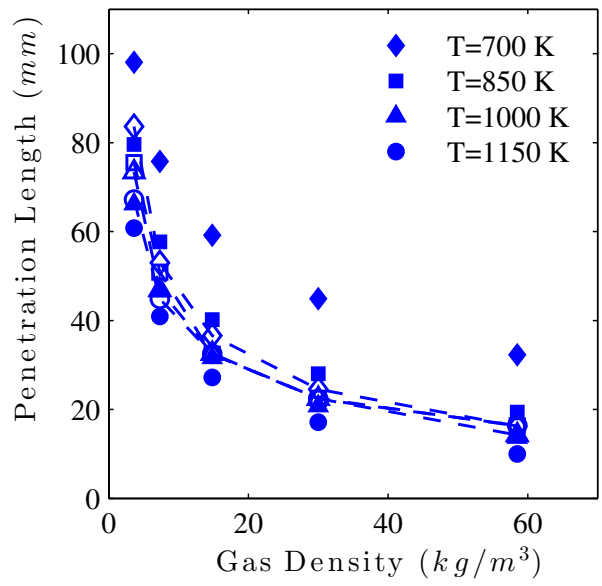

(a)

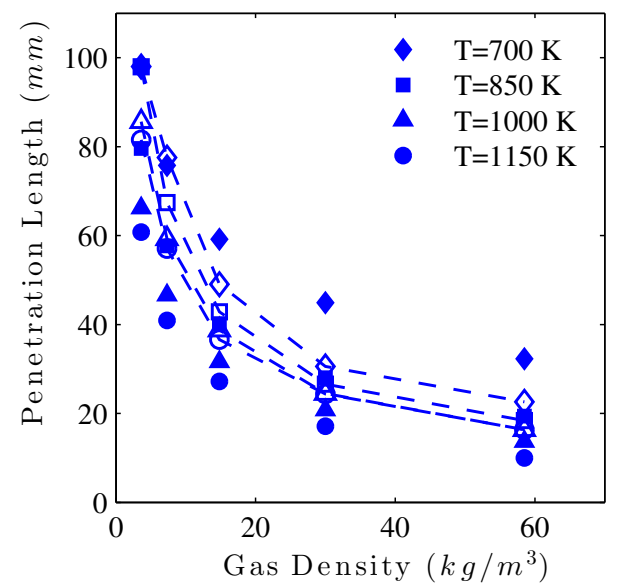

(b)

Figure 12: Liquid penetration length for different gas temperatures and densities with lumped evaporation model, $(\mathrm{a}) B_{1}=40, C_{R T}=0.10,(\mathrm{~b})$ $B_{1}=40, C_{R T}=0.18$. Fuel: n-hexadecane.

pressure and temperature are 15.13 and 1.60 , respectively, which imply supercritical conditions. Although the conditions are also supercritical for lower gas densities of $14.8 \mathrm{~kg} / \mathrm{m}^{3}$ and $7.3 \mathrm{~kg} / \mathrm{m}^{3}$, the effect on the penetration length does not seem to be significant for these conditions. It is probable that while the liquid length over-prediction is not significant, the effect of supercritical evaporation on the fuel vapor distribution is appreciable. The computational and experimental results indicate that the penetration length decreases on increasing gas temperature and density. However, the effects of gas temperature and density on the spray length are more significant at lower values of these variables. The gas density effect is strongly non-linear. The effect of gas temperature is also non-linear, but to a lesser extent. This can be explained by higher energy content of the entrained gas at higher temperatures and consequently faster evaporation rates. At higher gas densities, the total mass of entrained air increases and more energy is available for the fuel evaporation. All of these indicate that the penetration length is significantly dependent on the amount and energy of the entrained air in the spray zone.

Figure 12 compares the experimental results with the numerical results obtained with the lumped droplet model for the same spray conditions, for two different RT breakup constants, $C_{R T}=0.10$ and 0.18 . It is clear that the lumped model is unable to predict the liquid penetration lengths for the wide range of conditions studied in this paper. While $C_{R T}=0.10$ gives a good match for a gas temperature of $1000 \mathrm{~K}$ and a decent comparison for $850 \mathrm{~K}$, the penetration lengths at higher temperatures are overpredicted and those at $\mathrm{T}=700 \mathrm{~K}$ are significantly underpredicted by the model. By increasing $C_{R T}$ to 0.18 , the predictions for $\mathrm{T}=700 \mathrm{~K} \mathrm{im}$ prove but there is overprediction of experimental results for most other cases. Overall, the LES results indicate that the lumped model is less sensitive to changes in the gas temperature, while the trend of penetration length decreasing with the gas density seems to be followed. The lumped model is not able to fully capture the effect of temperature on the penetration length mostly because of constant physical properties and the assumption of uniform droplet temperature and concentrations. As compared to the lumped model, the variable property multicomponent model provides a better match with the experimental data at various temperatures.

\subsubsection{Multicomponent Liquid Sprays}

In this section, spray simulations are conducted with LES and more complex heat and mass transfer models for multicomponent liquids. Four different fuel mixtures from Table 1 are considered as surrogates for commercial grade Diesel2: D2N, D6N, CFA and FD9A. Figure 13 shows the numerically simulated $97 \%$ spray length of the diesel surrogates for various gas temperatures. For the case with the ambient gas temperature of $700 \mathrm{~K}$ (Figure 13(a)), the trend of nonlinear decrease of liquid length with gas density is well followed but the experimental values are considerably under-predicted by LES with all surrogate fuel models. As the gas temperature is increased to $850 \mathrm{~K}-1150 \mathrm{~K}$ (Figures 13(b) - 13(d)), there is an improvement in the numerical results, but the experimental values are still under- 


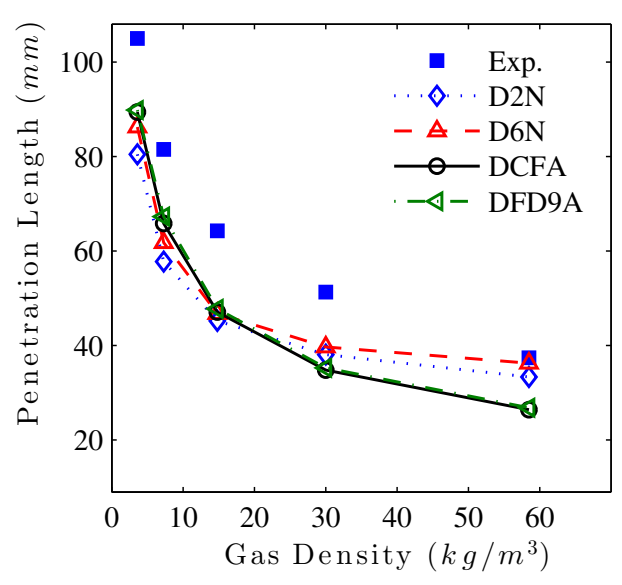

(a)

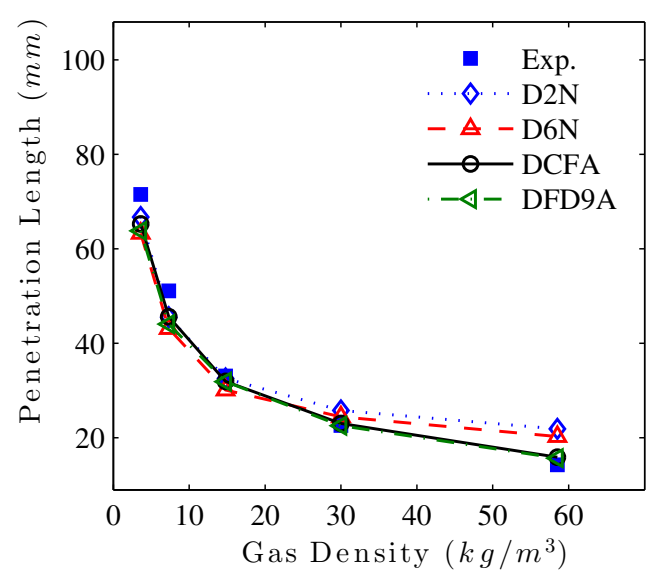

(c)

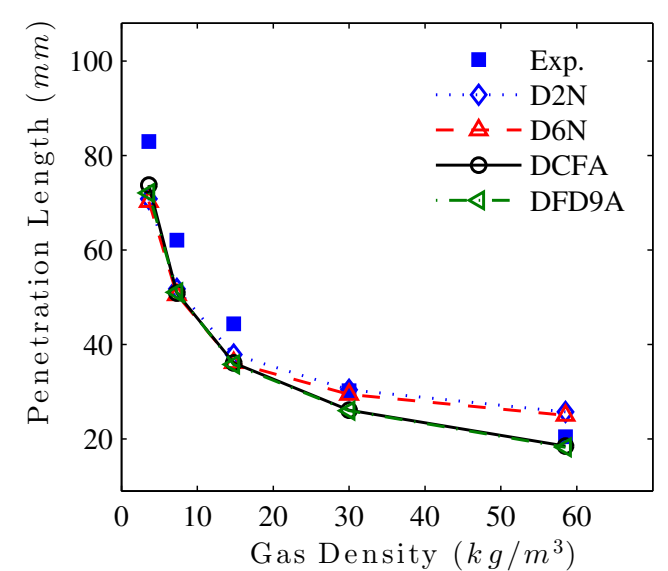

(b)

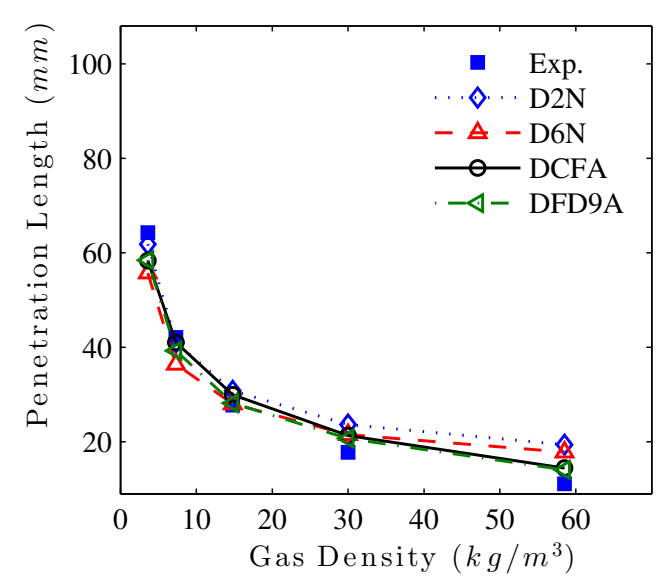

(d)

Figure 13: Variation of $97 \%$ penetration length of surrogate diesel fuels with gas density for different gas temperatures as predicted by LES. (a) $T_{g}=700 \mathrm{~K}$, (b) $T_{g}=850 \mathrm{~K}$,(c) $T_{g}=1000 \mathrm{~K}$, and (d) $T_{g}=1150 \mathrm{~K}$.

predicted. D2N has the smallest liquid length at low temperatures and densities and the highest at high temperatures and densities. The liquid lengths of the 8 species surrogates CFA and FD9A are nearly the same at all temperatures and are the highest at lower temperatures and pressures as compared to other surrogates, while the liquid lengths of D6N are generally in between the 2 and 8 species surrogates. Figure 14 shows the $99 \%$ liquid length obtained by LES with different surrogates. Evidently, there is a considerable improvement in the numerical results for all surrogates and at all temperatures. The liquid lengths predicted by LES with all the surrogates are in good agreement with experiment at higher temperatures of $1000 \mathrm{~K}$ and $1150 \mathrm{~K}$. The liquid lengths at $850 \mathrm{~K}$ are slightly underpredicted. However, at gas temperature of $700 \mathrm{~K}$, the liquid lengths are still underpredicted, although the 8 species surrogates predict them better than other surrogates, specially at lower temperatures and densities. The difference between $97 \%$ and $99 \%$ liquid lengths can be explained through the preferential evaporation of lighter fuel species over heavier components. The heavier species (C18-C20) persist longer and tend to become the major components of smaller droplets at the tip of the spray. This explains the better prediction of the liquid lengths by the 8 species surrogates at lower temperatures and densities, especially when $99 \%$ liquid mass criterion is used since these surrogates have higher amounts of the heavier species. CFA, DCFA and D6N have $27.3 \%, 29.8 \%$, and $15.79 \%$ of C18C20 species by mass, while D2N does not have any of these species. Figure 15 demonstrates the effect of 


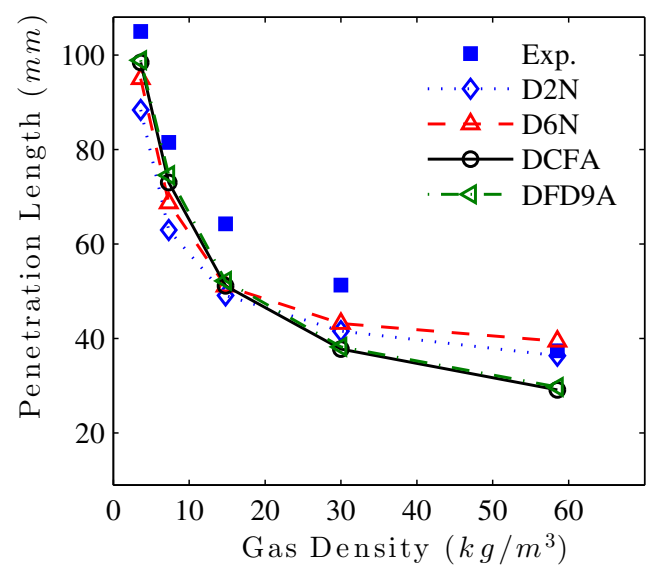

(a)

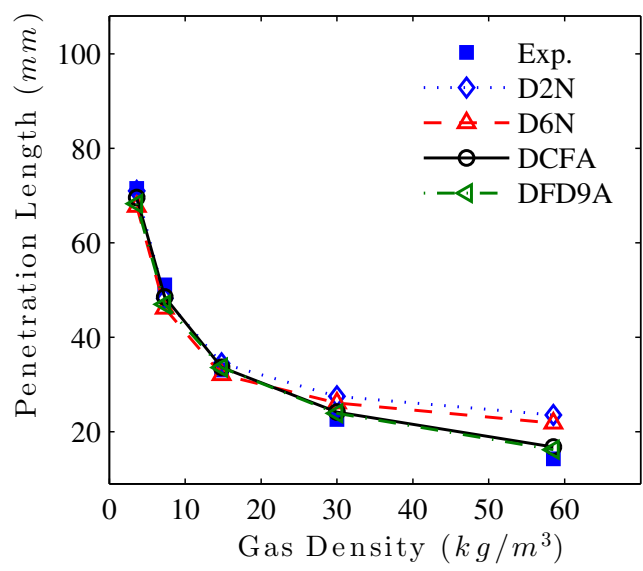

(c)

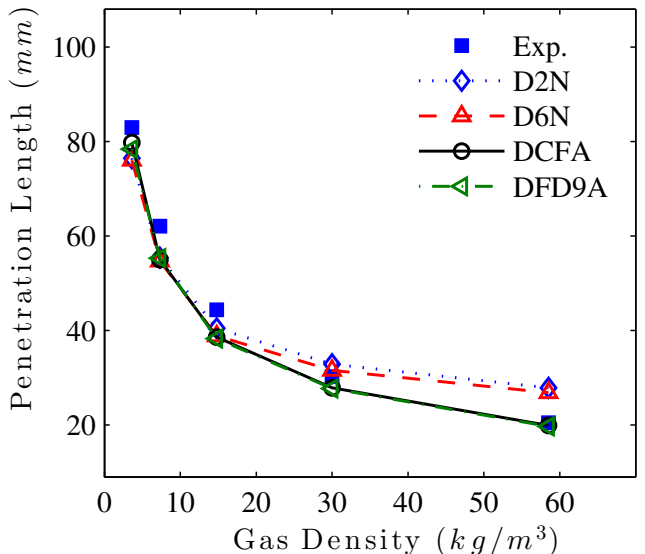

(b)

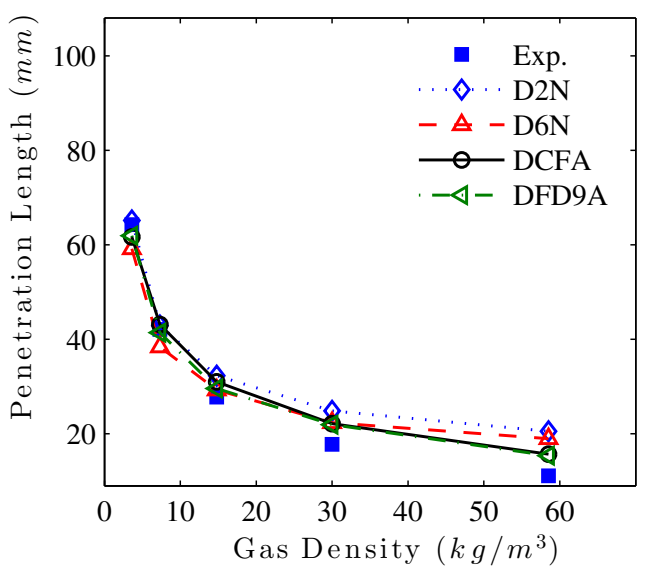

(d)

Figure 14: Variation of $99 \%$ penetration length of surrogate diesel fuel with gas density for different gas temperatures as predicted by LES. (a) $T_{g}=700 \mathrm{~K}$, (b) $T_{g}=850 \mathrm{~K}$, (c) $T_{g}=1000 \mathrm{~K}$, and (d) $T_{g}=1150 \mathrm{~K}$.

the presence of heavier species by comparing the 99 $\%$ liquid length of the heaviest species in the mixtures with the experimental results. n-octadecane $\left(\mathrm{C}_{18} \mathrm{H}_{38}\right)$ is the heaviest component in D6N and CFA, while neicosane $\left(\mathrm{C}_{20} \mathrm{H}_{42}\right)$ and 1-methylnaphthalene $\left(\mathrm{C}_{11} \mathrm{H}_{10}\right)$ are the heaviest components in FD9A and D2N, respectively. The comparisons in 15 indicate that the liquid length of the heaviest species matches the experimental results reasonably well at all temperatures for the mixtures containing C18-C20. The liquid length of 1methylnaphthalene in D2N falls considerably short of the experimental results at gas temperature of $700 \mathrm{~K}$, whereas the lengths of n-octadecane in D6N and CFA and n-eicosane in FD9A are in good agreement. This also indicates that it might be reasonable to compare the numerical liquid lengths of the heaviest species of the fuel mixture with the experimental results. It is not clear whether the presence of heavier components near the tip of the spray has any effect on the experimental results obtained based on light intensity.

The slower evaporation rates of the heavier species and their persistence in liquid form near the tip of the spray also has a significant effect on the distribution of the species in the vapor phase. Figure 16 compares the mass fraction contours of some of the components of D6N in the vapor phase during the evaporation process. The spray parcels are sized proportional to the mass fraction of the fuel component in the contour plot. For example, in Figure 16(a), each spray parcel is scaled proportional to the mass fraction of toulene in the parcel. Thus, the reduction in the size of the parcels indicates the reduction in the mass fraction of Toluene in the 


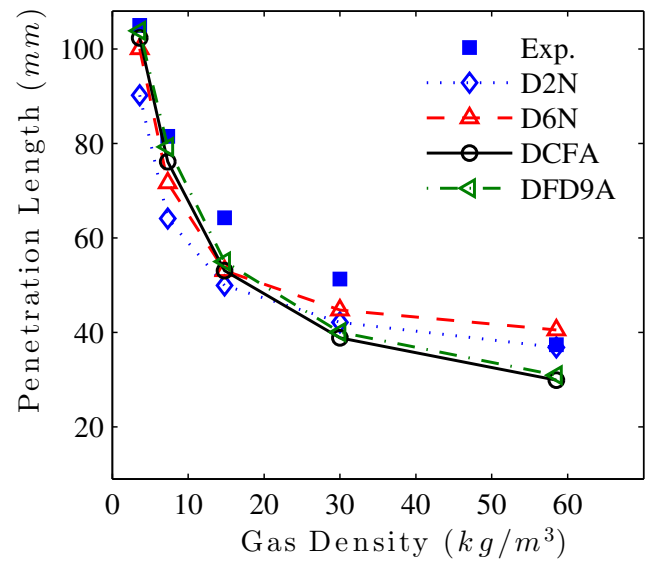

(a)

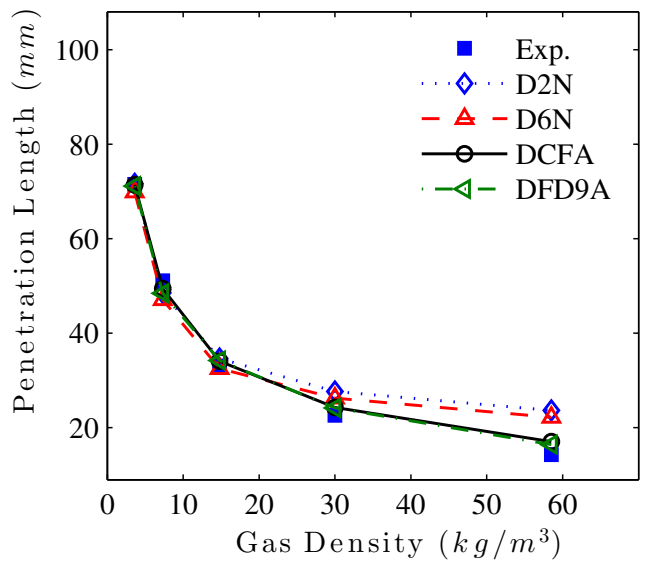

(c)

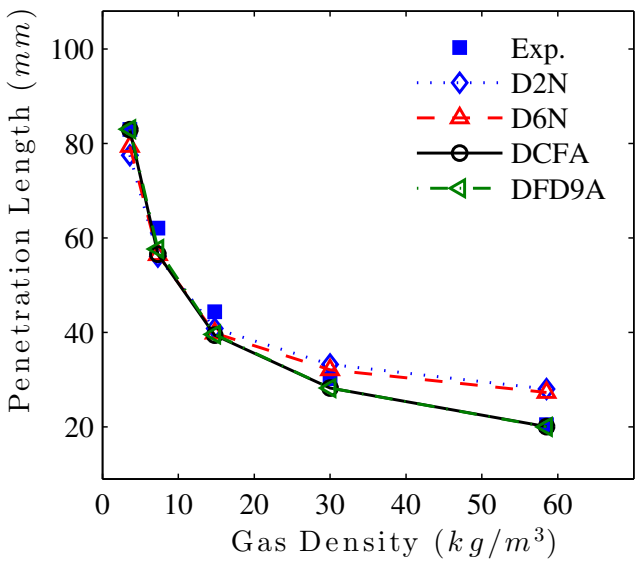

(b)

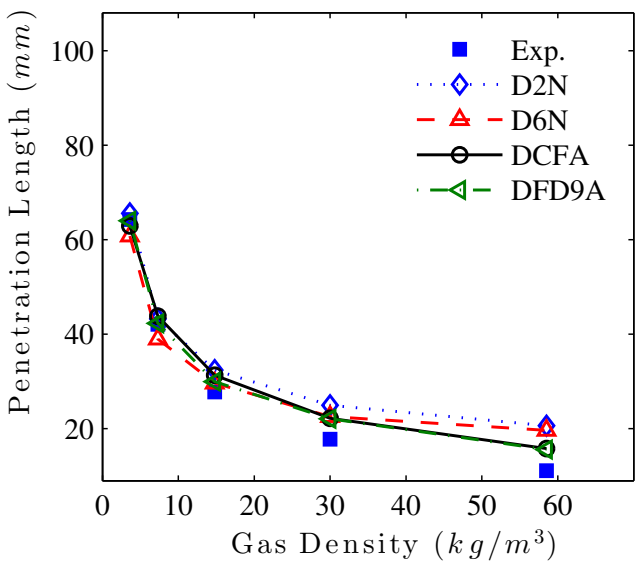

(d)

Figure 15: Variation of $99 \%$ penetration length of the heaviest species of the surrogate diesel fuel with gas density for different gas temperatures as predicted by LES. The heaviest species are: 1 -methylnaphthalene for D2N, n-octadecane for D6N and CFA, and n-eicosane for FD9A. (a) $T_{g}=700$ $\mathrm{K}$, (b) $T_{g}=850 \mathrm{~K}$, (c) $T_{g}=1000 \mathrm{~K}$, and (d) $T_{g}=1150 \mathrm{~K}$.

liquid phase as the jet penetrates into the chamber. This is because toluene is the lightest and the most volatile species and evaporates first, forming a higher concentration in the part of the vapor plume closest to the injector. As the weight of the species increases and their volatility decreases, their concentration in the central and downstream regions of the vapor plume increases (Figures 16(b) - 16(c)). The highest weight and least volatile component, n-octadecane, has relatively higher concentrations in the central region and regions near the tip of the vapor plume (Figure 16(d)). This preferential evaporation and concentration of the fuel species in the vapor phase can have a significant effect on the combustion characteristics of the fuel and deserves further investigation. Only a qualitative view of the vapor phase distribution is presented here as relevant experimental data is not available for the case studied. Experimental vapor phase distribution data for diesel sprays is scarce in general as mentioned before. The LES code used in the current paper is perfectly capable of simulating complex, moving, engine geometries and has been used previously for simulations of a 3-valve DISI engine with the single component lumped model [54] and a twostroke opposed piston diesel engine [73] with the multicomponent evaporation model. Diesel engine data provided in Trost et al. [31] (discussed in the introduction) is thus being considered for future studies. In Figures 6 and 7 it was shown that the use of activity coefficients for modifying the Raoult's Law does not have a significant effect on the droplet diameter and temperature but the mass fraction profiles of species inside the droplet are affected. The mass fraction contours of D6N with 


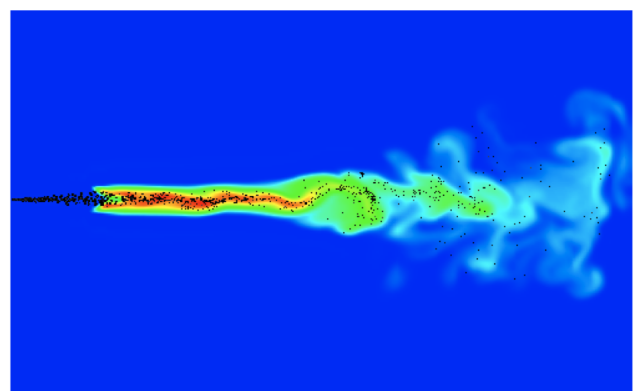

(a)

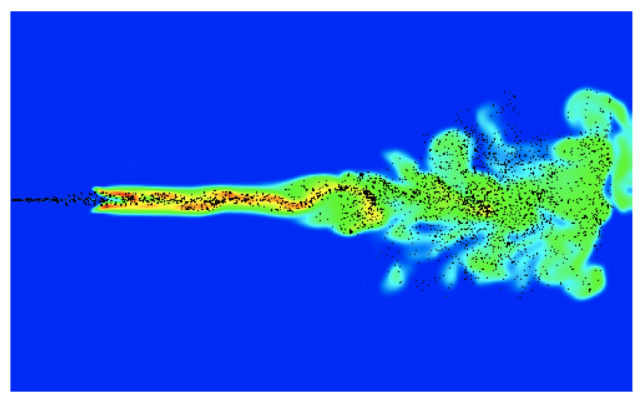

(c)

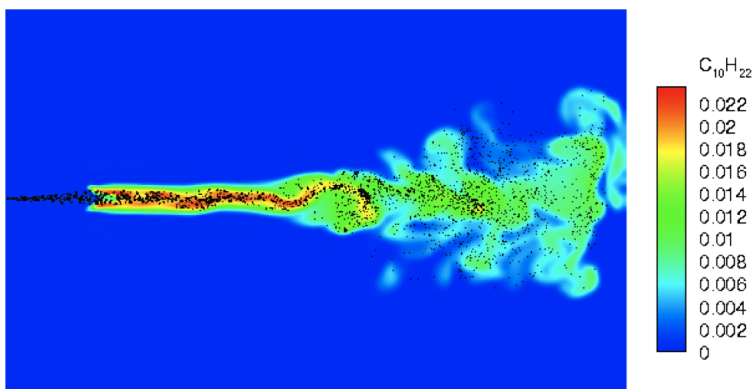

(b)

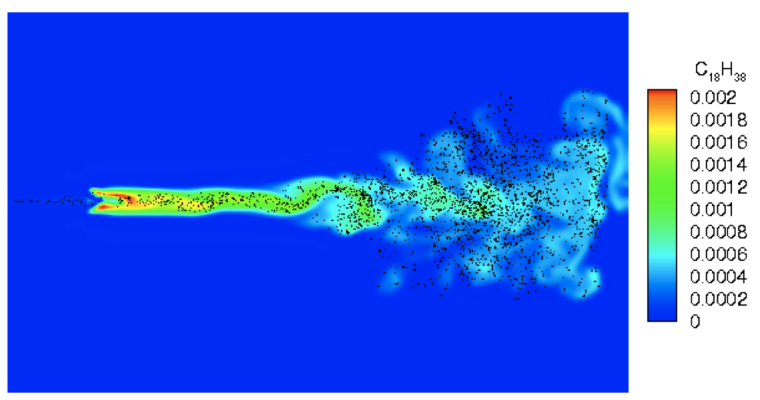

(d)

Figure 16: Vapor mass fraction contours for various components of D6N as predicted by LES. (a) toluene, (b) n-decane, (c) n-dodecane, and (d) $\mathrm{n}$-octadecane. The length of the domain in this figure are $108 \mathrm{~mm}$ and $65 \mathrm{~mm}$ in axial (x) and lateral (z) directions, respectively.

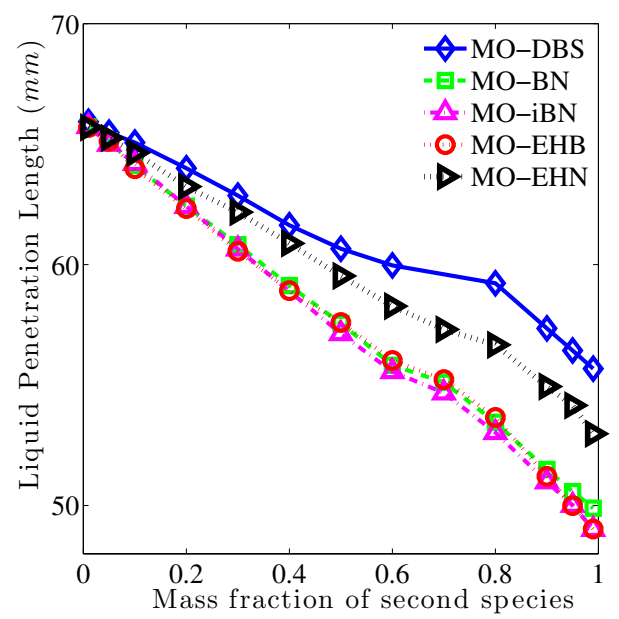

Figure 17: Liquid penetration lengths for biofuel spray at gas temperature and density $700 \mathrm{~K}$ and $7.3 \mathrm{~kg} / \mathrm{m} 3$, respectively, injection pressure 55 $\mathrm{MPa}$, nozzle diameter $0.100 \mathrm{~mm}$, and injected liquid temperature $436 \mathrm{~K}$.

and without activity coefficients (not shown) are found to be nearly the same in the initial portion of the vapor plume, but there are noticeable differences, both in shape and mass fraction values, near the tip of the vapor plume. The penetration of the vapor plume is the same, but it is slightly wider in the simulations conducted with activity coefficients. Similar patterns were observed in the components of D6N, n-dodecane and n-octadecane. As in the case of single droplets, the inclusion of real liquid effects was found not to have a significant influence on the mean spray quantities; while the liquid penetration does not change, the distribution of components 
in the vapor phase changes. This implies that real liquid effects should be considered while studying the behavior of multicomponent fuel surrogates, but the overall effect on the combustion performance requires further detailed study. A set of biofuel spray simulations, with the droplets having the same composition as the stationary biofuel droplets in Section 3.1.2 were conducted in order to understand the spray characteristics of biofuel blends. In these simulations, the gas temperature and density are $700 \mathrm{~K}$ and $7.3 \mathrm{~kg} / \mathrm{m}^{3}$, the injection pressure is $55 \mathrm{MPa}$, the nozzle diameter is 0.100 $\mathrm{mm}$ and the injected liquid temperature is $436 \mathrm{~K}$. Figure 17 presents the spray penetration length results for some of the bi-component mixtures considered. Most of the trends observed in the single drop studies are followed but there are also some significant differences. The mixtures containing iBN show the lowest penetration lengths due to it being more volatile than BN, DBS and EHN. The penetration lengths of 2-EHB are similar to $\mathrm{iBN}$. The mixtures of MO-BN penetrate more into the domain as compared to $\mathrm{iBN}$ and 2-EHB, specially when the percentage of MO is low. This is due to the slightly higher latent heat and lower pressure of $\mathrm{BN}$, the effects of which were not readily apparent in the case of a single drop. The liquid lengths of 2-EHN and DBS mixtures are higher than other species and MODBS mixtures have the highest liquid lengths. In the single drop simulations, lifetimes for MO-EHN mixtures were higher. Since the total mass of the fuel injected is higher in the case of MO-DBS mixtures due to the higher density of DBS as compared to 2-EHN, the energy required to evaporate the fuel droplets is more. The air entrained by the liquid jet is nearly the same for both cases, thus the MO-DBS mixtures take longer to evaporate and penetrate further. In all the fuel mixtures studied here, the variation of liquid penetration lengths is nearly linear, with the penetration lengths increasing with increase in proportions of MO. There is a change in the slope of the lines when the mass fraction of the second species decreases from 0.7 to 0.6 ; the lines become closer to each other and the difference in liquid lengths decreases significantly as the mass fraction of MO increases. This shows that the difference in the properties of the components significantly decreases as the percentage of the least volatile component MO increases. The results for biofuel mixtures obtained above give an estimate of the effect of different components on the spray process and is made possible by the use of the multicomponent evaporation model. Understanding the effect of various biofuel mixtures on the overall combustion process requires reliable chemical kinetics mechanisms for these mixtures and more detailed stud- ies.

\section{Summary and Conclusions}

A multicomponent fuel heat transfer and evaporation model has been implemented and used for large eddy simulations (LES) of evaporating fuel droplets and sprays. The model solves the one-dimensional mass and energy equations for the mass fraction and temperature profiles inside each of the droplets with a finite volume method and includes real liquid effects on the evaporation process through activity factors. For a single droplet, the variable property multicomponent results were shown to compare well with the constant property lumped model in the limiting conditions. The LES model along with variable property multicomponent droplet heat and mass transfer models and the Kelvin-Helmholtz - Rayleigh-Taylor (KH-RT) droplet breakup model, is used for numerical simulations of spray experiments conducted at the Sandia National Laboratory [62] for single component $n$-hexadecane and multicomponent diesel fuels. The numerically predicted liquid penetration lengths for $n$-hexadecane were found to be in better agreement with the experimental results when the multicomponent heat and mass transfer models are used instead of the much simpler lumped model. The LES results for liquid lengths of four different multicomponent diesel surrogates with 2-8 components indicate that the mixtures with larger number of species, with a wider range of properties, and with heavier species in the range $\mathrm{C} 18-\mathrm{C} 20$, give a better prediction of the spray penetration lengths as compared to experiments. The effect of real liquid properties on the evaporation process was also evaluated and it was observed that while the single droplet lifetime and liquid spray penetration are relatively unaffected, the liquid mass fractions inside the droplet and the mass fractions of different components in the evaporated vapor plume as well as the shape of the vapor plume are influenced by the real liquid effects. The multicomponent evaporation model was also used for studying the behavior of single droplets and sprays of different biofuel blends. The numerical results show that for biofuel mixtures with Methyl Oleate (MO), the droplet lifetimes and penetration lengths increase with increase in proportions of the low volatility MO.

Based on the above results, it can be safely stated that variable property models are important and should be used for predicting the evaporation of both single component and multicomponent fuels in droplet and spray calculations. With fully variable properties, the droplet lifetime and consequently the spray length, are 
predicted to be shorter. Changes in the liquid density and latent heat of vaporization have a direct effect on the droplet lifetime, while changes in the liquid thermal conductivity have little effect. Real liquid effects on the vapor-liquid equilibrium should be included in the evaporation modeling of multicomponent fluids since they affect the droplet surface vapor mass fractions and consequently the mass fraction profiles in both liquid and gas phases.

Spray length decreases non-linearly with increasing pressure and to a lesser extent with temperature, with decreasing sensitivity to changes in ambient gas conditions at higher temperatures and pressures. These trends are captured by the LES with variable property multicomponent and KH-RT breakup models. It is to be noted that the spray penetration length is sensitive to the spray breakup process and incorporating a more comprehensive breakup model might be a necessary step in achieving a very good comparison with the experimental results. Nevertheless, the use of multicomponent evaporation model improves the prediction of spray length and fuel vapor distribution for single component fuels and enables the calculation of complex fuels like diesel using surrogate mixtures. The model is not, however, fully accurate. Over-prediction of spray length at higher gas temperatures may be due to the gas conditions being supercritical for the liquid fuel components, especially at higher gas pressures. The prediction of the spray quantities like spray length is also dependent on the composition of the mixture and requires an accurate knowledge of fuel composition. For non-reacting sprays, radiation effects are expected to be negligible since the gas temperatures are not high. However, in order to completely rule out the effect of radiation, a model for absorption of thermal radiation in a semitransparent spherical droplet [74] was implemented and was found to have no effect on the droplet evaporation rates in the range of temperatures considered. The multicomponent evaporation model allows the study of the effect of fuel composition on the fuel spray and evaporation characteristics and can be a utilized as a tool in the design of fuels to meet specific requirements. The discrete component nature of the evaporation model allows the coupling of evaporation and combustion but requires a better knowledge of the composition of the fuel and the availability of detailed chemical reaction mechanisms for the individual species and their mixtures.

\section{Acknowledgements}

This work was supported by the U.S. Department of Energy under agreement DE-FC26-07NT43278. Addi- tional support was provided by the Defense Logistics Agency under agreement DFARS-252235-7010. Computational resources were provided by the High Performance Computing Center at Michigan State University.

\section{References}

[1] A. A. Amsden, P. J. O'Rourke, T. D. Bulter, KIVA-1l: A Computer Program for Chemically Reactive Flows with Sprays, Los Alamos National Laboratory Report No LA-11560-MS UC-96, 1989.

[2] R.S. Miller, J. Bellan, Direct numerical simulation of a confined three-dimensional gas mixing layer with one evaporating hydrocarbon-droplet-laden stream, Journal of Fluid Mechanics 384 (1999) 293-338.

[3] R.S. Miller, K. Harstad, J. Bellan, Evaluation of equilibrium and non-equilibrium evaporation models for many-droplet gasliquid flow simulations, International Journal of Multiphase Flow 24 (1998) 1025-1055.

[4] T. Almeida, F. A. Jaberi, Large eddy simulation of a dispersed particle-laden turbulent round jet, International Journal of Heat and Mass Transfer 51 (2008) 683-695.

[5] T. Almeida, F. A. Jaberi, Direct numerical simulations of a planar jet laden with evaporating droplets, International Journal of Heat and Mass Transfer 49 (2006) 2113-2123.

[6] F. A. Jaberi, F. Mashayek, Temperature decay in two-phase turbulent flows, International Journal of Heat and Mass Transfer 43 (2000) 993-1005.

[7] F. Mashayek, F. A. Jaberi, Particle dispersion in forced isotropic low Mach number turbulence, International Journal of Heat and Mass Transfer 42 (1999) 2823-2836.

[8] F. A. Jaberi, Temperature fluctuations in particle-laden homogeneous turbulent flows, International Journal of Heat and Mass Transfer 41 (1998) 4081-4093.

[9] W. A. Sirignano, Fluid Dynamics and Transport of Droplets and Sprays, New York: Cambridge University Press, 1999.

[10] S. S. Sazhin, Advanced models of fuel droplet heating and evaporation, Progress in Energy and Combustion Science 32 (2) (2006) 162-214.

[11] J. Tamim, W. Hallett, A continuous thermodynamics model for multicomponent droplet vaporization, Chem. Eng. Sci. 18 (1995) 2933-2942.

[12] W. Hallet, A simple model for the vaporization of droplets with large numbers of components, Combustion and Flame 121 (2000) 334-344.

[13] A. Lippert, R. Reitz, Modeling of multicomponent fuels using continuous distributions with application to droplet evaporation and sprays, SAE 972882, 1997.

[14] L. Zhang, S. Kong, Modeling of multicomponent fuel vaporization and combustion for gasoline and diesel spray, Chem. Eng. Sci. 64 (2009) 3688-3696.

[15] L. Zhang, S-C. Kong, Vaporization modeling of petroleumbiofuel drops using a hybrid multicomponent approach, Combustion and Flame 157 (2010) 2165-2174.

[16] R. B. Landis, A.F. Mills, Effect of internal diffusion resistance on the evaporation of binary droplets 5 th Int. Heat Transfer Cont (Tokyo) Paper B7-9, 1974.

[17] W.A. Sirignano, C.K. Law, Transient heating and liquid phase mass diffusion in droplet vaporization Evaporation-Combustion of Fuels (Advances in Chemistry Series vol 166) ad J T Zung (Washington, DC: American Chemical Society) pp 1-26, 1978.

[18] P. Lara-Urbaneja, W.A. Sirignano, Theory of transient multicomponent droplet vaporization in a convective field gasifica- 
tion, 18th Symp. (Int.) Combustion (Pittsburgh, PA: The Combustion Institute) pp 1365-74, 1981.

[19] S.K. Aggarwal, Modeling of a dilute vaporizing multicomponent fuel spray, International Journal of Heat and Mass Transfer 30 (1987) 291-302.

[20] G. Chen, S.K. Aggarwal, T.A. Jackson, G.L. Switzer, Experimental study of pure and multicomponent fuel droplet evaporation in a heated air flow, Atomization and Sprays 7 (1997) 317-337.

[21] M. Renksizbulut, M. Bussmann, Multicomponent droplet evaporation at intermediate Reynolds numbers, International Journal of Heat and Mass Transfer 3 (1993) 2827-35.

[22] Y. Zeng, C.F. Lee, A multicomponent-fuel film-vaporization model for multidimensional computations, Propulsion and Power 16 (2000) 964-73.

[23] Y. Zeng, C.F. Lee, Modeling of spray vaporization and air-fuel mixing in gasoline direct-injection engine SAE Paper, 2000-OI0537, 2000.

[24] Y. Ra, R.D. Reitz, A vaporization model for discrete multicomponent fuel sprays, International Journal of Multiphase Flow 35 (2009) 101-117.

[25] L. Zigan, I. Schmitz, A. Flgel, M. Wensing, A. Leipertz, Structure of evaporating single- and multicomponent fuel sprays for 2nd generation gasoline direct injection, Fuel 90 (2011) 348363.

[26] D. Han, R.R. Steeper, An LIF equivalence ratio imaging technique for multicomponent fuels in an IC engine, Proceedings of the Combustion Institute 29 (2002) 727-734.

[27] P.L. Kelly-Zion, J.P. Styron, C.F. Lee, R.P. Lucht, J.E. Peters, A.R. White. Multicomponent liquid and vapour fuel measurements in the cylinder of a port-injected, spark ignition engine, 27 th symposium (international) on combustion, The Combustion Institute, 1998.

[28] B. Williams, P. Ewart, R. Stone, Multicomponent quantitative PLIF: robust engineering measurements of cyclic variation in a firing spray-guided gasoline direct injection engine. SAE 200801-1073, 2008.

[29] H. Krmer, S. Einecke, C. Schulz, V. Sick, S.R. Nattrass, J.S Kitching, Simultaneous mapping of the distribution of different fuel volatility classes using tracer-LIF tomography in an IC engine. SAE 982467, 1998.

[30] G. Tea , G. Bruneaux, J. T. Kashdan, C. Schulz, Unburned gas temperature measurements in a surrogate Diesel jet via twocolor toluene-LIF imaging, Proceedings of the Combustion Institute, 33 (2011) 783-790.

[31] J. Trost , L. Zigan, A. Leipertz, D. Sahoo, P.C. Miles, Fuel concentration imaging inside an optically accessible Diesel engine using 1-methylnaphthalene planar laser-induced fluorescence (PLIF), International Journal of Engine Research, 15(6) (2014) 741-750.

[32] M.A. Gorokhovski, V.L. Saveliev, Analyses of Kolmogorov's model of breakup and its application into Lagrangian computation of liquid sprays under air-blast atomization, Physics of Fluids 15, 184 (2003).

[33] A. Irannejad, F. Jaberi, Large eddy simulation of turbulent spray breakup and evaporation, International Journal of Multiphase Flow 61 (2014) 108-128.

[34] A. Irannejad, F. Jaberi, Numerical study of high speed evaporating sprays, International Journal of Multiphase Flow 70 (2015) 58-76.

[35] I. Silverman, W.A. Sirignano, Multi-droplet interaction effects in dense sprays, International Journal of Multiphase Flow 20 (1994) 99-116.

[36] C.K. Westbrook, W.J. Pitz, P.R. Westmoreland F.L. Dryer, M. Chaos, P. Osswald, K. Kohse-Hoinghaus, T.A. Cool, J. Wang,
B. Yang, N. Hansen, T. Casper, A detailed chemical kinetic reaction mechanism for oxidation of four small alkyl esters in laminar premixed flames, Proceedings of the Combustion Institute 32(1) (2009) 221-228.

[37] A. Demirbas, Biofuels sources, biofuel policy, biofuel economy and global biofuel projections, Energy Conversion and Management, 49(8) (2008) 2106-2116.

[38] A. Demirbas, Progress and recent trends in biofuels, Progress in Energy and Combustion Science 33(1) (2007) 1-18.

[39] E. Toulson, C. Allen, D.J. Miller, T. Lee. Modeling the autoignition of oxygenated fuels using a multistep model, Energy Fuels 24 (2010) 888-896.

[40] E. Toulson, C. Allen, D.J. Miller, H.J. Schock, T. Lee. Optimization of a multi-step model for the auto-ignition of Dimethyl Ether in a rapid compression machine, Energy Fuels 24 (2010) 3510-3516

[41] E. Toulson, C. Allen, D.J. Miller, J. McFarlane, H.J. Schock, T. Lee. Modeling the autoignition of fuel blends with a multistep model, Energy Fuels 25 (2011) 632-639.

[42] C. Allen, E. Toulson, D.L.S. Hung, H. Schock, D. Miller, T. Lee. Ignition characteristics of diesel and Canola biodiesel sprays in the low-temperature combustion regime. Energy Fuels 25 (2011) 2896-2908.

[43] C.W. Squibb, H. Schock, C. Allen, T. Lee, M. Poort, K. Crayne, Optical diagnostic combustion comparisons of pump diesel with bio-derived diesel blends in an optical DI diesel engine, SAE Technical Paper 2012-01-0868, 2012.

[44] C. Allen, E. Toulson, D. Tepe, H. Schock, D. Miller, T. Lee, Characterization of the effect of fatty ester composition on the ignition behavior of biodiesel fuel sprays, Fuel 111 (2013) 659669.

[45] D. Torres, P.J. O'Rourke, A discrete multicomponent fuels model for GDl engine simulations, ILASS Americas 14th Annual Conference on Liquid Atomization and Spray Systems (Dearborn, MI), 2001.

[46] D.J. Torres, P.J. O'Rourke, A.A. Amsden, Efficient multicomponent fuel algorithm, Combustion Theory and Modelling 7 (2003) 67-86.

[47] D.J. Torres, P.J. O'Rourke, A.A. Amsden, A discrete multicomponent fuel model, Atomization and Sprays 13 (2-3) (2003) 131172.

[48] B. Abramzon, W.A. Sirignano, Droplet vaporization model for spray combustion calculations, International Journal of Heat and Mass Transfer 32 (1989) 1605-1617.

[49] J. Gmehling, P. Rasmussen, Aa. Fredenslund, Vapor-liquid equilibria by UNIFAC group contribution. Revision and extension 2, Industrial and Engineering Chemistry Process Design and Development 21 (1982) 118-127.

[50] J.M. Smith, H.C. Van Ness, Introduction to Chemical Engineering Thermodynamics, McGraw-Hill Book Company, 1987.

[51] J.E. Dennis, R.B. Schnabel, Numerical methods for unconstrained optimization and nonlinear equations, Englewood Cliffs,N.J.; Prentice Hall, pp 169-189, 1983.

[52] B. E. Poling, J. M. Prausnitz, J. P. O'Connell, The properties of gases and liquids, 5th Edition, New York: McGraw-Hill, c2001.

[53] A. Afshari, F.A. Jaberi, T. I.-P. Shih, Large-eddy simulation of turbulent flow in an axisymmetric dump combustor, AIAA Journal 46(7) (2008) 1576-1592.

[54] A. Banaeizadeh, A. Afshari, H. Schock, F. Jaberi, Large-eddy simulations of turbulent flows in internal combustion engines, International Journal of Heat and Mass Transfer 60 (2013) 781796.

[55] J. Smagorinsky, General Circulation Experiments with the Primitive Equatons. 1. The Basic Experiment, Monthly Weather Review 91(3) 1963 99-164. 
[56] A. Yoshizawa, Statistical theory for compressible turbulent shear flows, with the application to subgrid modeling, Physics of Fluids 29 (1986) 2152-2164.

[57] M. Germano, U. Piomelli, P. Moin, W.H. Cabot, A dynamic subgrid-scale eddy viscosity model, Physics of Fluids A 3 (1991) 1760-1765.

[58] P. Moin, K. Squires, W. Cabot, S. Lee, A dynamic subgrid-scale model for compressible turbulence and scalar transport, Physics of Fluids A 3 (1991) 2746-2757.

[59] D.K. Lilly, A proposed modification of the Germano subgridscale closure method, Physics of Fluids A 4 (1992) 633-635.

[60] W.-W. Kim, S. Menon, LES of turbulent fuel/air mixing in a swirling combustor, AIAA Paper No. AIAA-1999-200 (1999).

[61] C. Stone, S. Menon, Simulation of fuel-air mixing and combustion in a trapped-vortex combustor, AIAA Paper No. AIAA2000-478 (2000)

[62] D.L. Siebers, Liquid-Phase Fuel Penetration in Diesel Sprays, SAE 980809, 1998

[63] W. Hentschel, K.-P Schindler, O. Haahtela, European Diesel Research IDEA- Experimental Results from DI diesel Engine Investigations, SAE 941954, 1994.

[64] O. Mathieu, N. Djebaili-Chaumeix, C-E. Paillard, F. Douce, Experimental study of soot formation from a diesel fuel surrogate in a shock tube, Combustion and Flame 156 (2009) 1576-1586.

[65] J.T. Farrell, N.P. Cernansky, F.L. Dryer, D.G. Friend, C.A. Hergart, C.K. Law, R.M. McDavid, C.J. Mueller, A.K. Patel, H. Pitsch, Development of an experimental database and kinetic models for surrogate diesel fuels, SAE 2007-01-0201, 2007.

[66] C.J. Mueller, W.J. Cannella, T.J. Bruno, B. Bunting, H.D. Dettman, J.A. Franz, M.L. Huber, M. Natarajan, W.J. Pitz, M.A. Ratcliff, K. Wright, Methodology for formulating diesel surrogate fuels with accurate compositional, ignition-quality, and volatility characteristics, Energy and Fuels 26 (2012) 32843303.

[67] J.D. Naber, D.L. Siebers, Effects of gas density and vaporization on penetration and dispersion of diesel sprays, Transactions of the SAE, Vol. 105, Sect. 3, pp. 82-111, 1996.

[68] C. Baumgarten, Mixture Formation in Internal Combustion Engines, Springer-Verlag 2006.

[69] J.C. Beale, R. D. Reitz, Modeling spray atomization with the Kelvin-Helmholtz/Rayleigh-Taylor hybrid model, Atomization and Sprays 9(6) (1999) 623-650.

[70] L.M. Ricart, R.D. Reitz, J.E. Dec, Comparisons of diesel spray liquid penetration and vapor fuel distributions with in-cylinder optical measurements, Journal of Engineering for Gas Turbines and Power, 122, (2000) 588-595.

[71] S. Som, Development and validation of spray models for investigating diesel engine combustion and emissions, $\mathrm{PhD}$ thesis, University of Illinois at Chicago, Chicago, IL, 2009.

[72] R. N. Dahms, J. Manin, L. M. Pickett, J. C. Oefelein, Understanding high-pressure gas-liquid interface phenomena in Diesel engines, Proceedings of the Combustion Institute, 34 (2013) 1667-1675.

[73] S. Srivastava, Modeling and simulation of evaporating spray, turbulent flow, and combustion in internal combustion engines, $\mathrm{PhD}$ thesis, Michigan State University, East Lansing, MI, 2015.

[74] L. Dombrovsky, S. Sazhin, Absorption of thermal radiation in a semi-transparent spherical droplet: a simplified model, International Journal of Heat and Fluid Flow 24 (2003) 919-927. 